\title{
CAMPANAS CERÁMICAS PREHISPÁNICAS Y LA PRESENCIA DE TRÁFICO caravanero tardío en la cuenca de Nasca, sur del Perú
}

\author{
Viviana Siveroni $^{a}$
}

\section{Resumen}

En los Andes, el tema del tráfico caravanero prehispánico ha sido ampliamente estudiado especialmente en el norte de Chile y en el noroeste argentino. En el Perú, en cambio, las investigaciones arqueológicas tradicionalmente llegaron sólo a esbozar aspectos muy generales de los modos de explotación de los rebaños de camélidos. Recientemente, varios investigadores han aportado nuevas propuestas sobre el modo de tenencia de camélidos durante la época prehispánica en la Costa Norte, los que se basan en buena cuenta en estudios isotópicos de colecciones óseas. Este articulo pretende aportar al tema añadiendo detalles sobre otro caso prehispánico diferente de tenencia de camélidos, esta vez de la Costa Sur peruana. El punto de partida de esta reconstrucción son las primeras evidencias arqueológicas de campanas cerámicas de la cuenca norte del rio Grande de Nasca, la que se complementa con información de ejemplares adicionales provenientes de otros sitios de la región. Este grupo inicial de campanas proviene del sitio arqueológico Ciudad Perdida de Huayuri, en la quebrada de Santa Cruz, y se asocia particularmente al Horizonte Tardio (1470-1532 AD). Luego de un análisis del contexto en las que se encontró, sostengo que las campanas cerámicas se usaron como campanas de llamas (Lama glama) o cencerros, y a la luz de información etnográfica, su presencia en Huayuri sugiere la participación de las unidades domésticas en la organización del tráfico caravanero. A un nivel interpretativo más general, y a la luz de documentos coloniales tempranos y de la distribución espacial de los ejemplares adicionales, se sugiere la existencia de un eje de circulación norte-sur a lo largo de la costa atravesando el desierto de Nasca e Ica, quizá extendiéndose desde Ica al norte hasta Arequipa al sur.

Palabras clave: tráfico caravanero, campanas de cerámica, cencerros, camélidos, unidades domésticas, Huayuri, Nasca, Costa Sur del Perú

\section{Abstract \\ CERAMIC BELLS AS INDICATORS OF LLAMA CARAVAN TRAFFIC IN LATE PREHISPANIC NASCA, PERU}

The topic of Prehispanic llama caravan trade has been widely examined in the archaeology of Northern Chile and Norwestern Argentina. Comparatively speaking, in Peru the topic has been previously explored only minimally. Recently, research based on bone isotope analyses from sites in the North Coast of Peru is adding to our knowledge of Prehispanic camelid herd management systems. The present article aims at advancing yet a different case of camelid herd exploitation, this time from the South Coast of Peru. This interpretation stems from the first evidence of ceramic bells from Huayuri, a Late Prehispanic Nasca settlement (1100-1532 AD) with a clear Late Horizon occupation $(1470-1532 \mathrm{AD})$, and is complemented with information of other examples from the region not formally reported before. After presenting the context of the findings, I propose these ceramic bells were llama bells. As suggested by ethnographies of llama (Lama glama) herders, the presence of these bells in the domestic area of the site strongly suggests a direct involvement of some of Huayuri's domestic units in the organization of the caravans. At a more general level, descriptions from colonial documentation and the regional distributions of additional bells, support the idea a northsouth axis of circulation crossing the deserts of Ica and Nasca, from Tacaraca in Ica to Arequipa to the south of Nasca.

Keywords: Andean caravans, Llama bells, household organization, South American camelids, herder's residences, Huayuri, Nasca, South Coast of Peru

a Institute of Archaeology, University College London

Correo electrónico: maskaypacha@gmail.com 


\section{Introducción}

En el área andina, el tema del tráfico caravanero prehispánico ha sido ampliamente explorado para mostrar una diversidad de modos de organización en el tiempo y en el espacio. Los ejemplos más notables provienen de casos arqueológicos en el norte del Chile, el sur de Bolivia y el noroeste argentino (Núñez y Nielsen 2011). Estos estudios exploran desde varias perspectivas teóricas las distintas dimensiones del tráfico caravanero, tales como la variabilidad esperada en los sistemas de asentamiento que subyacen cada modelo interpretativo, la escala de las rutas y los rasgos arqueológicos que habitan los espacios «vacíos» entre asentamientos nodales, además de las características de los objetos intercambiados (Núñez y Dillehay 1979; Nielsen 2000; Berenguer 2002; Briones et al. 2005; Ross et al. 2008). Por mucho tiempo, y en contraste con la variabilidad organizativa que emerge de los estudios arriba mencionados, los modelos caravaneros del área central andina, hasta recientemente, solían asociarse recurrentemente al modelo complementario o de colonización (Berenguer 2002: 7) que se deriva de la interpretación de las fuentes etnohistóricas (Murra 1975, 1980). En el caso del Horizonte Tardío, las caravanas se interpretan como instituciones centrales de la economía del Estado inca, cuyos derechos de gestión y beneficios recaían en el Estado (Shimada y Shimada 1985; Spurling 1992; Watson 2009). Sin embargo, la exploración de casos arqueológicos particulares que brinden un panorama más amplio y diverso al dado por las fuentes escritas es limitada (Murra 1965, para los vacíos en la investigación sobre el tema aún vigentes en la actualidad). En este sentido, son bien recibidos los recientes trabajos que discuten la variabilidad en las escalas y tipo de intercambio, y modos organizativos del tráfico caravanero (v.g. Tripcevich 2010; Szpak et al. 2014) y los avances en la determinación de crianza in situ de camélidos en la costa norte del Perú, al menos, desde el Horizonte Temprano (v.g. Goepfert et al. 2013; Szpak 2013; Goepfert y Prieto 2016; Szpak et al. 2016).

En particular, para el área de Nasca (Fig. 1), la mayoría de trabajos arqueológicos que han abordado el tema del tráfico caravanero lo han hecho tangencialmente. Se asume que las sociedades de la costa no participaron en la organización del tráfico caravanero, pues se cree que la crianza de camélidos en el desierto no fue posible o fue poco probable (Valdez 1988; Conlee 2000; Vaughn 2000; Horn et al. 2009; Renneberg et al. 2009, aparte véase Orefici 1994 para un caso excepcional e interesante). Generalmente, los restos de camélidos encontrados en sitios arqueológicos de la costa se interpretan como productos del intercambio con poblaciones serranas. Debajo de estas interpretaciones, subyace el prejuicio de que los camélidos no se adaptaron al desierto costero, lo cual ha desencadenado una falta de escrutinio del registro arqueológico. Sin embargo, los camélidos domésticos son animales, cuyo aparato digestivo está adaptado para subsistir a partir del forraje de bajo valor nutritivo, que es típico del desierto (Jouany 2000). La vegetación de lomas y dunas podría haber provisto de forraje durante viajes entre valles. Al respecto, el arqueólogo Luis Angulo Paredes (comunicación personal 2016) indica haber visto camélidos que consumían plantas de Tillandsia sp.; por su parte, el ingeniero Lorenzo Solier (comunicación personal 2016) reporta el uso de semillas de algodón como complemento de forraje de ganado vacuno, que podría haberse usado en la alimentación de camélidos. Teniendo el mismo pasado evolutivo que los camellos, los camélidos han heredado también mecanismos fisiológicos que permiten subsistir en ecosistemas áridos, como, por ejemplo, la proliferación de glándulas sudoríparas y la protección de la piel con su propia fibra (Bonacic y Franklin 2007). Pese a estas ventajas adaptativas, casos de aridez extrema imponen un límite a la distribución de estos animales domésticos, más aún cuando se les demanda trabajo físico. Por esto, se deben tomar en cuenta los estudios paleoclimáticos que sugieren que el área de Nasca sufrió un proceso de desertificación que se intensificó en el Horizonte Tardío. Sin embargo, estos mismos estudios indican que el clima revertió para el Período Intermedio Tardío, lo que generó condiciones más húmedas que las actuales (Eitel y Mächtel 2009). Inclusive, Mächtel $e t$ al. (2009) sugieren que los habitantes de Huayuri aprendieron a elaborar sistemas colectores de agua - comparables a los khadins de la India - para poderse adaptar a las nuevas condiciones medioambientales. Por tanto, hay varias razones para mantener abierta la posibilidad de que la crianza de camélidos en el desierto de Nasca fue posible y este artículo intenta contribuir con este debate. 


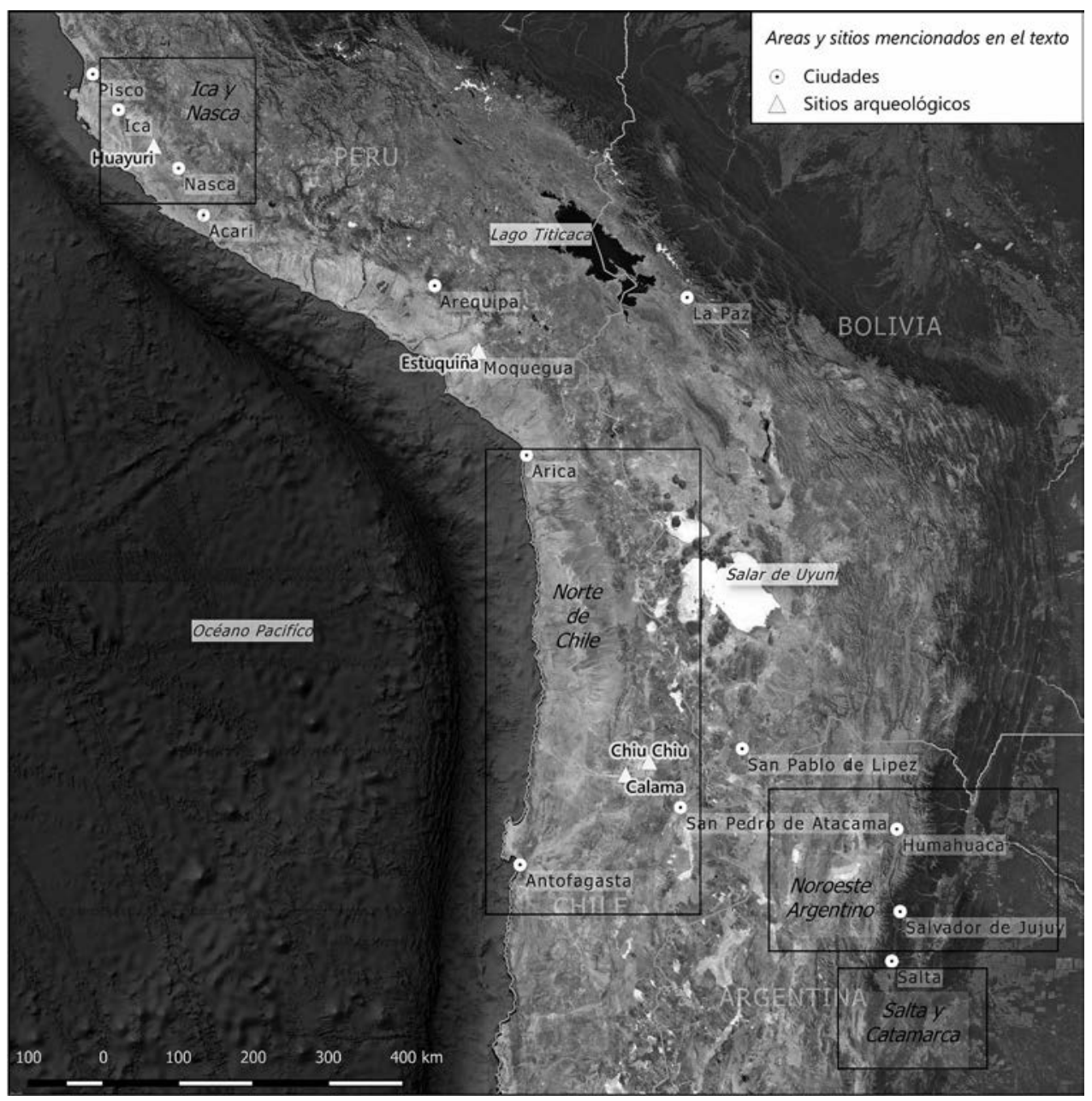

Figura 1. Localización de las áreas y sitios mencionados en el texto (mapa: Viviana Siveroni basado en imágenes de Google Earth, 2017).

Los objetivos de este estudio son dos. El primero es presentar y discutir las primeras evidencias arqueológicas de campanas cerámicas reportadas para la cuenca del río Grande de Nasca, costa sur del Perú. Estos hallazgos provienen de las excavaciones en el sitio arqueológico Ciudad Perdida de Huayuri, en la quebrada de Santa Cruz, y se asocian a la ocupación del Horizonte Tardío en Nasca (1470 - 1532 d.C.). El segundo objetivo es sugerir — haciendo referencia a contextos arqueológicos de la costa sur del Perú y del norte de Chile, sur de Bolivia y Argentina, y datos etnográficos de Perú y Bolivia - que la función de estas campanas fue la de cencerros.

En la primera parte de este artículo, menciono las referencias de campanas de llamas encontradas en etnografías y contextos arqueológicos publicados con el fin de subrayar el tipo de vínculos entre estos artefactos y llameros en los Andes. En una segunda parte, presento un resumen breve del Período Prehispánico en Nasca para pasar, luego, a describir el sitio y el contexto de donde proviene las campanas que luego describo. En la parte final, discuto las consecuencias que tienen estos hallazgos de Huayuri en nuestro entendimiento del tráfico caravanero prehispánico en la costa sur del Perú. 


\section{Campanas, objetos rituales, y llameros en las etnografías andinas}

A través del trabajo de Jorge Flores Ochoa (Flores Ochoa 1983; Flores Ochoa y Fries 1989; Flores Ochoa et al. 1994), muchos de nosotros hemos conocido de la preeminencia de los llameros y pacocheros en las alturas sureñas del Perú y Bolivia. Más recientemente, trabajos como los de Axel Nielsen (2000), y los Patrice Lecoq y Sergio Fidel (2003) en Bolivia, entre otros muchos más (Dransart 1991, 2011; Stobart 1996; Göbel 2002), han ampliado nuestro entendimiento sobre la vida diaria de los pastores de puna y del desierto.

En particular, el trabajo de Nielsen $(2000,2001)$ ha contribuido a una mejor definición de los indicadores del tráfico caravanero. A partir de su trabajo etnoarqueológico con comunidades caravaneras en el norte de Argentina y el sur de Bolivia, Nielsen sugiere que el tipo de posesiones de los caravaneros es un indicador de su especialización económica (Fig. 2) y que es en las casas de los caravaneros que se guardan los objetos que se usan en los viajes de caravanas, así como los objetos rituales que se usan para las ceremonias de partida o llegada. Entre los objetos que se describen en estas etnografías, están las campanas y pecheras que se cuelgan de las llamas que presiden las caravanas, así como los costales, líos, cuerdas y ondas que se usan en el viaje mismo (Nielsen 2001: 184-185).

Como Nielsen (2000) menciona, este conjunto de artefactos es el mejor indicador de la localización de las residencias de caravaneros que los objetos mismos del intercambio, pues estos últimos pueden ser redistribuidos inmediatamente después de terminado el viaje, dentro de la población, o pueden ser reclamados por los grupos que patrocinaron la empresa.

Más aun, muchas etnografías muestran que, cuando los rebaños de camélidos son el centro de la economía doméstica de un grupo, estos se asocian a ritos propiciatorios destinados a protegerlos y reproducirlos (Flores Ochoa 1974; Isbell 1978). Las campanas que cuelgan del cuello de las llamas, denominadas «delanteras» y que tienen una función central en el viaje — pues ayudan a organizar y mantener al rebaño unido en la ruta-, pueden además tener un lugar central en estos rituales propiciatorios. En los grupos reportados por Lecoq y Fidel (2003: 46), las campanas son usadas para challar o libar al final del viaje y se utilizan como recipiente para beber el alcohol. Además, estas campanas se asocian a conceptos de fertilidad, abundancia, cosecha y similar, y tienen el poder de comunicarse con hombres y animales y curar enfermedades (Lecoq y Fidel 2003: 46).

Estas etnografías sugieren que las campanas llameras - o cencerros - tienen una significancia tanto utilitaria como ideológica en las sociedades pastoriles y agropastoriles de los Andes centrales. La siguiente sección revisa la evidencia de su origen prehispánico.

\section{Evidencias arqueológicas de campanas llameras en los Andes}

Los casos documentados de campanas llameras en contextos arqueológicos en los Andes provienen de varias localidades del noroeste de Argentina; Chile; Bolivia; e inclusive de Perú, del cementerio de Estuquiña, valle de Moquegua (Ambrosetti 1902; Boman 1908; Clark 1993; Pérez de Arce 2001; Latcham 1938 citado en Berenguer 2002;). Esta área fue un espacio de intenso tráfico caravanero prehispánico que conectó los valles costeros de Chile —en particular, toda la región de Atacama y Antofagasta - con el interior del continente hasta el noroeste argentino y el sur de Bolivia (Berenguer 2002) (Fig. 1).

Como lo resume Berenguer en su trabajo de intercambio caravanero en la región de Antofagasta, es Uhle (1913 citado en Berenguer 2002:172) el primer investigador que establece una asociación explícita entre las campanas que aparecen en las tumbas del Período Intermedio Tardío de Calama (río Loa, provincia del Loa, Chile), y el tráfico caravanero del desierto de Atacama y de las regiones del interior.

Las descripciones de los contenidos de las tumbas de Calama y otros sitios en el valle del Loa y alrededores listan, además de las campanas y sus badajos, tarabitas o ganchos de atalaje, sogas de lana, moluscos de varios tipos, plumas de aves de la selva y pescado seco, restos que indican 


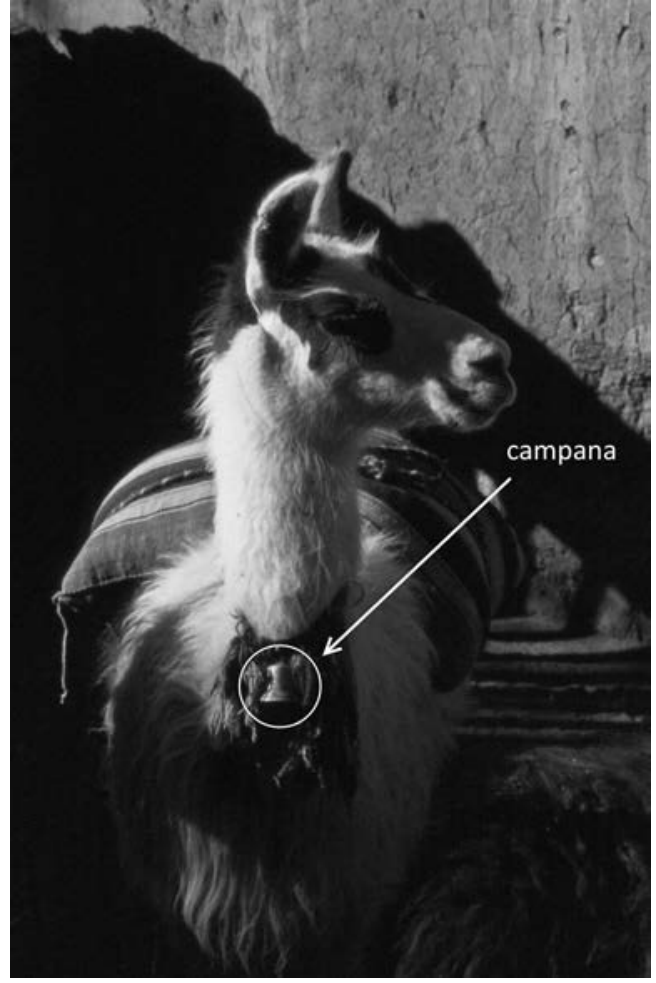

Figura 2. Llama delantera con campana y pechera, caravana de ceramistas itinerantes, lago Titicaca (foto: cortesia de Bill Sillar).

un intercambio de bienes entre el interior y la costa de Antofagasta. En el Perú, se han reportado campanas de madera en el valle de Moquegua. Clark (1993: fig. 4.8b) reproduce tres de estas campanas provenientes del cementerio de Estuquińa de una tumba del Período Intermedio Tardío (Fig. 1).

Estas campanas son de madera, así como sus badajos. El cuerpo sonoro de estos ejemplares tiende a ser tronco cónico o acampanado con perfil oval en la sección transversal (Fig. 3). La campana es más ancha en la apertura y el extremo opuesto presenta dos agujeros por los que pasa la cuerda que sujeta los badajos. Los tamaños reportados son variables. La campana es descrita por Boman (1908: 744, fig. 175); esta mide 19 centímetros de alto, 23 por 9,3 centímetros en la boca y 9,5 por 6,2 centímetros en la parte superior, mientras que una del desierto de Atacama, reportada por Pérez de Arce (2001: fig. 4), mide 16 centímetros. Las campanas encontradas en Moquegua son muy similares a las primeras, aunque no tan altas y más pequeñas: miden aproximadamente cinco centímetros de alto y siete por tres centímetros de ancho en la abertura (Clark 1993: fig. 4.8b). La superficie del ejemplar descrito por Boman (1908: 744) está alisada al exterior y sin alisar con las huellas de manufactura al interior.

Los badajos de estas campanas son filamentos alargados o palillos de madera mínimamente trabajados, cercanos a un centímetro de grosor, con un extremo irregular pero romo y el otro con un orificio que tiene la función de sujetar los badajos al cuerpo sonoro. En este sentido, son muy parecidos a punzones romos o agujas romas (Figs. $3 \mathrm{~b}$ y 4 ). Al ser de elaboración simple y material mundano, encontramos pocos badajos de madera reportados en la literatura, pero es evidente que debieron usarse en manojos de cuatro o más, como se aprecia en las figuras.

Aparte de las campanas de madera directamente asociadas a caravanas de llamas y que citamos previamente, encontramos una serie de campanas metálicas en contextos prehispánicos que es pertinente discutir aquí. Gudemos $(1998,2013)$ realiza un recuento de cuatro tipos de campanas metálicas prehispánicas recurrentes en diferentes partes del área centro-sur andina: las piramidales 

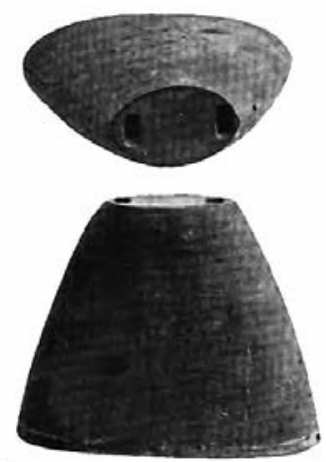

a.

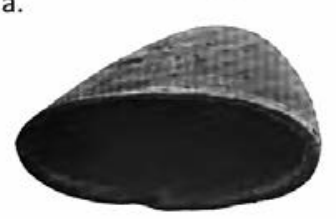

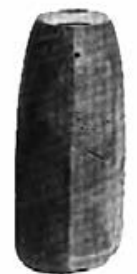

b.

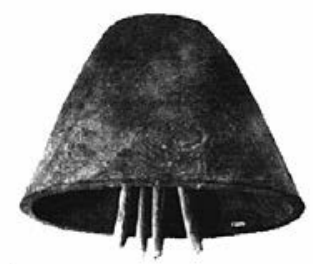

c.

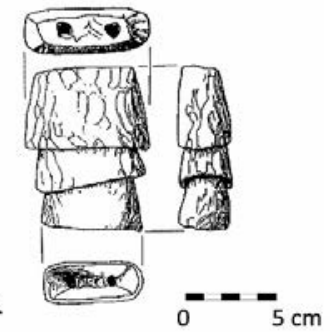

Figura 3. Campanas de madera de varias procedencias dibujadas a diferentes escalas: a, Calama, Chile (Boman 1908: Fig. 175, altura $19 \mathrm{~cm}$ ); b, San Pedro de Atacama, Argentina (Pérez de Arce 2001: Fig. 4, altura 16 cm.; Estuquiña, Perú (Clark 1993: Fig. 4.8b, escala es $5 \mathrm{~cm}$ ) (composición/edición por Viviana Siveroni).

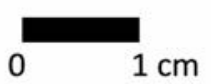

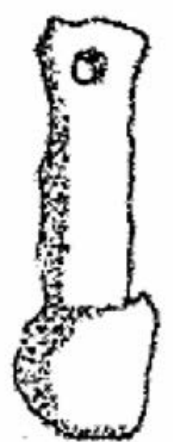

a. b.

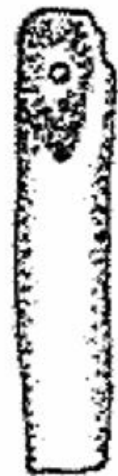

Figura 4. Badajos de metal de la quebrada de Humahuaca, Argentina (basado en Angiorama 1991: Fig. 5.29 y 5.30; editado por Viviana Siveroni).

plegadas, las cónicas, las tronco-cónicas y las tronco-cónicas de perfil ovalado santamarianas (Gudemos 1998: 114). Las campanas troncocónicas y las troncocónicas santamarianas (Fig. 5) son relevantes aquí, pues han sido asociadas al tráfico caravanero. Estas se encuentran primordialmente en cuatro regiones: la región de Salta y Catamarca en Argentina, la región de Jujuy, el norte de Chile y en la costa sur peruana (Gudemos 1998, 2013). Aparentemente, las campanas santamarianas - relacionadas con la cultura material del mismo nombre del Período de Desarrollos Regionales (900-1470 d.C.) de Catamarca y Salta, Argentina- parecen haber tenido una fuerte influencia estilística en el desarrollo de las campanas troncocónicas posteriores que se encuentran en áreas aledañas, como el norte de Chile y la provincia de Jujuy, entre otras (Gudemos 2013). De este modo, las formas tronco-cónicas de la parte norte de Chile son claramente influenciadas por el desarrollo de los ejemplares en el área Santamariana. Aunque las campanas santamarianas parecen haber tenido un uso ritual y emblemático (Pérez de Arce 2001), las campanas troncocónicas del norte 


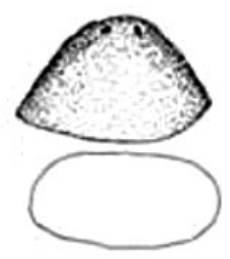

a.

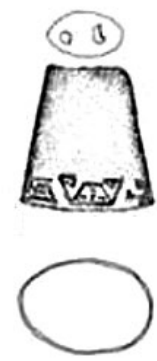

e.
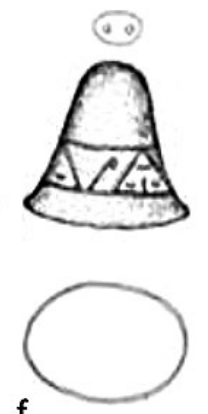

f.

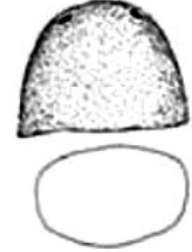

b.

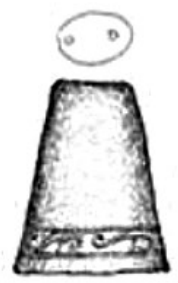

g.

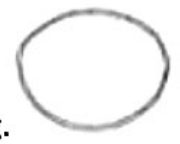

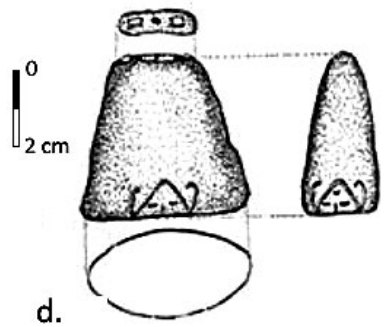

d.

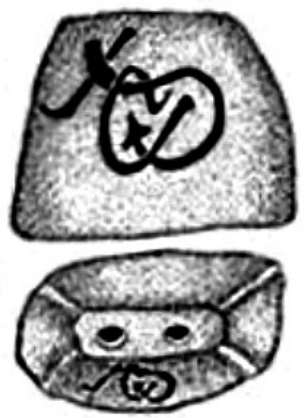

Figura 5. Campanas tronco-cónicas de metal y cerámica de varias regiones. Campanas metálicas: a-c, Ica; $d$, Nasca; e-g, Jujuy. Campanas de cerámica: h, Catamarca (rediagramadoleditado por Viviana Siveroni a partir de Gudemos 2013: Figura 9; la escala es aproximada).

de Chile a las que Gudemos designa «pequeñas campanas troncocónicas trasandinas de bronce» (2013: 589) y que corresponden al Período Intermedio Tardío y al Período Colonial Temprano fueron usadas como cencerros de llamas, tal cual sucede con su contraparte de madera en la misma región y que hemos descrito con anterioridad. Del mismo modo, se cree que las campanas del área de Jujuy, al norte del área Santamariana, están relacionadas a los intercambios interregionales con el norte de Chile. Digno de destacar, Gudemos reporta una campana de troncocónica de oro proveniente de Nasca muy similar, estilísticamente hablando, a las campanas del noroeste argentino y norte de Chile (2013: Fig. 9). Lamentablemente, no existe información sobre su contexto o fecha. Es interesante que, incluidas en el mismo grupo de campanas troncocónicas, se presenta un subgrupo de seis campanas de cobre y bronce registradas como provenientes del valle de Ica y fechadas en el Período Intermedio Tardío (Fig. 5a-5c).

En cuanto a las características de las campanas troncocónicas, estas son de metal forjado, o fundido de cobre o bronce; además, como todas las anteriores, presentan al menos dos agujeros en la base del cuerpo sonoro (Gudemos 1998: 119-124). Las santamarianas tienen perfil oval en la sección transversal cerca a la boca y pueden ser bastante altas, entre 12 y 35 centímetros de altura. Por su parte, las campanas del norte de Chile son más pequeñas y tienen en promedio siete centímetros de altura (Gudemos 2013: 119-121). La campana troncocónica de Nasca es de oro y es muy similar formalmente a las chilenas: tienen una altura de aproximadamentecinco 5 centímetros y un perfil oval en la sección transversal (Fig. 5). Por último, las campanas de Ica son pequeñas, de aproximadamente cinco centímetros de altura y apertura, y formalmente se diferencian de las anteriores pues tienen la base del cuerpo sonoro externamente convexa, por lo cual parecen haber sido hechas a partir de un cuenco semiesférico de metal achatado en sus lados (Fig. 5a-5c).

Existe poca información sobre los bajados de estas campanas metálicas. Según Gudemos, las campanas de metal de forma piramidal plegadas suelen tener badajos del mismo material que el del cuerpo sonoro, aunque se han reportado badajos de piedra, hueso, cerámica y otros metales (1998: 15). Angiorama (2001: figs. 5.29 y 5.30) ilustra dos badajos de metal preincas provenientes 
del noroeste argentino; uno de ellos se muestra muy parecido a una aguja gruesa con ojal y de punta roma (Fig. 4).

Con estas descripciones de las campanas como referentes formales, paso a describir los hallazgos de campanas y badajos en la Ciudad Perdida de Huayuri (Figs. 1 y 6). Antes, describo brevemente el contexto sociocultural del período al que se asocian.

\section{El período prehispánico Tardío en los valles norteños de Nasca}

Aun sabemos poco sobre la naturaleza de la sociedad prehispánica Tardía de la cuenca del río Grande de Nasca (Fig. 6). Sobre la base de una comparación de los restos de asentamientos inca en los valles de la costa sur, Menzel (1959) propuso que las sociedades tardías que poblaron los valles de Ica y Chincha eran grupos complejos y jerarquizados, mientras que los aquellos del área de Nasca fueron categorizados como grupos que carecían de instituciones de control sociopolítico de escala regional.

Años después, otras investigaciones han añadido más detalles a este esquema. En los valles de Chincha e Ica, sabemos que el dominio político de sus jefes durante el período preinca incluía, en ambos casos, el total de las poblaciones que ocupaban un valle o más allá, aspecto que está sustentado en la existencia de un patrón de asentamientos jerárquico. A esto se suma la existencia de un sistema vial vinculando sitios especializados. Los sitios de función especializada se definen por la presencia de espacios públicos y arquitectura monumental de patrón congruente y recurrente, y palacios de una calidad y/o tamaño mucho mayor que el de las viviendas del común, y por la clara evidencia de producción artesanal patrocinada o de especialización a tiempo completo. Además, existen patrones mortuorios que reflejan diferenciación socioeconómica marcada (para un resumen de esta evidencia, véase Shimada 2000; Covey 2008; Dulanto 2008; Nigra et al. 2014).

La imagen arriba expuesta es muy distinta de la reconstruida para el área de Nasca. Para los valles norteños de Nasca, donde Huayuri se localiza, lamentablemente, no existe aún un trabajo que haya sintetizado la totalidad de la información recobrada durante los diversos proyectos de prospecciones (Browne y Baraybar 1988; Silverman 1991; Browne 1992; Reindel e Isla 1998; Reindel et al. 1999; Proulx 2007). Sin embargo, por el momento, podemos extraer algunas constantes de los informes individuales. Procesos tales como el crecimiento de población dentro de cada valle - que es un proceso general para el territorio de los Andes centrales - se manifiesta en Nasca en la formación de sitios grandes y aglutinados que llegan a tener entre 10 y 20 hectáreas. Ejemplos de asentamientos grandes y de traza compacta son Huayuri en Santa Cruz (Siveroni et al. 2004; Siveroni 2008), Pinchango Alto en el valle de Palpa (Reindel 2005), Sitio 220 en la confluencia del río Grande con el valle del Ingenio (Silverman 1991), y Los Colorados en la confluencia del río Grande con el río de Nasca (Proulx 2007) (Fig. 7). Dentro de cada valle, existe un número limitado de asentamientos que llegan a las seis hectáreas. Aunque algunos asentamientos grandes llegan a tener 20 hectáreas, estos no presentan clara evidencia de áreas de función especializada dentro de estos asentamientos que sean inequívocamente asignables al Período Intermedio Tardío. Por tanto, la existencia de élites locales con poder político y económico que sobrepase la escala del valle individual y, más aún, la dependencia entre asentamientos son difíciles de sustentar, al menos, en este punto de la investigación. El problema radica en la dificultad de diferenciar los sitios o áreas del Período Intermedio Tardío de aquellas fechables al Horizonte Tardío a partir del material cultural. Faltan estudios más detallados que refinen este aspecto (véase Sandweiss 1992 para una discusión de los problemas cronológicos).

Una visión distinta es la que brindan Conlee (2003, 2004) y Schreiber (Conlee y Schreiber 2006) sobre la ocupación tardía en los valles sureños de la cuenca del Nasca. Estas dos autoras identifican el patrón de asentamientos del Período Intermedio Tardío y proponen que las poblaciones de los diferentes valles estaban agrupadas bajo un cacicazgo. Al igual que el caso de las élites en el norte, las élites del sur también carecen de visibilidad en el registro arqueológico, aunque las autoras citadas aquí interpretan este rasgo no como la carencia de élites, sino como un reflejo de la naturaleza particular del poder que las sostiene (Conlee y Schreiber 2006). 


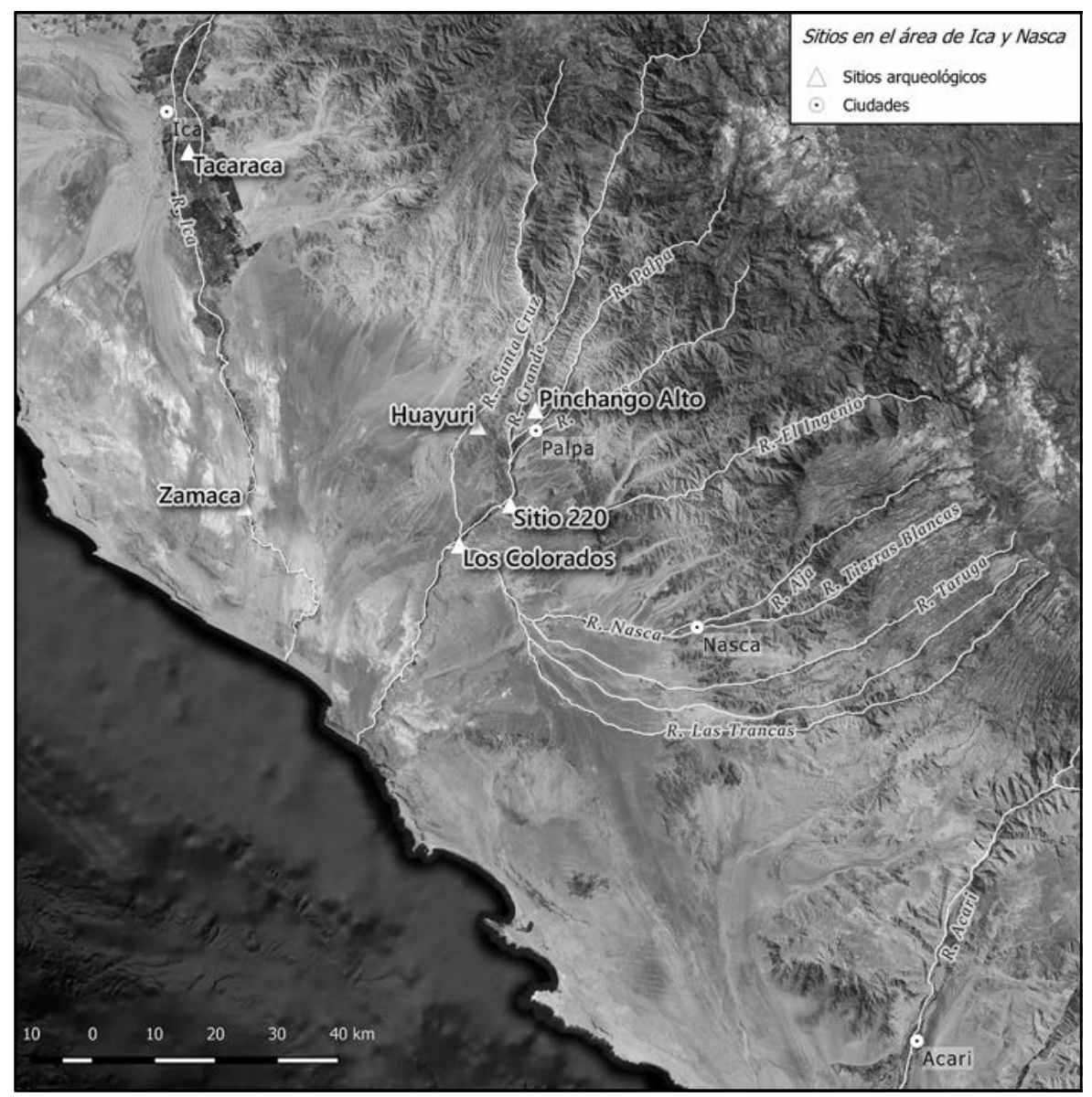

Figura 6. Sitios en el área de Nasca e Ica (mapa: Viviana Siveroni basado en imágenes de Google Earth, 2017).

\section{La quebrada de Santa Cruz y Huayuri}

La Ciudad Perdida de Huayuri es un asentamiento extenso y densamente poblado, y, por ende, típico del Período Tardío en la zona. Se ubica en la margen sur del valle bajo del río Santa Cruz — valle más norteño de la cuenca del río Grande de Nasca, y se extiende unas 20 hectáreas de las cuales al menos 12 presentan ocupación densa y continúa- (Figs. 6 y 7).

Gran parte de la ocupación en Huayuri se localiza en lo que Alfaro de Lanzone en 1975 llamó la Quebrada Principal (Fig. 7). Los posibles accesos naturales desde la pampa de las carretas a la Quebrada Principal están cerrados por medio de unos muros delimitadores ahora bastante destruidos. Mächtel et al. (2009) han sugerido que estos muros se usaron para recolectar agua de lluvias, pero esto no ha sido verificado con excavaciones. La arquitectura, así como la configuración espacial dentro de la Quebrada Principal, sugiere que esta es una unidad de asentamiento per se.

Un reconocimiento de la parte sur de esta quebrada permitió definir la existencia de un camino hacia el sur del asentamiento que conecta a Huayuri con un asentamiento contemporáneo localizado en la actual hacienda Huayuri (Fig. 7). La localización de muros delimitadores que restringen el acceso desde el norte tiene sentido en este contexto. Este sitio cercano a la hacienda actual es pequeño, y tiene arquitectura de planta ortogonal con muros de adobes y presenta un cementerio aledaño. A juzgar por las descripciones de Neudecker (1979), es del cementerio al sur dentro de este sitio que provienen las dos tumbas múltiples del estilo Ica, excavadas por Ubbelohde-Doering 


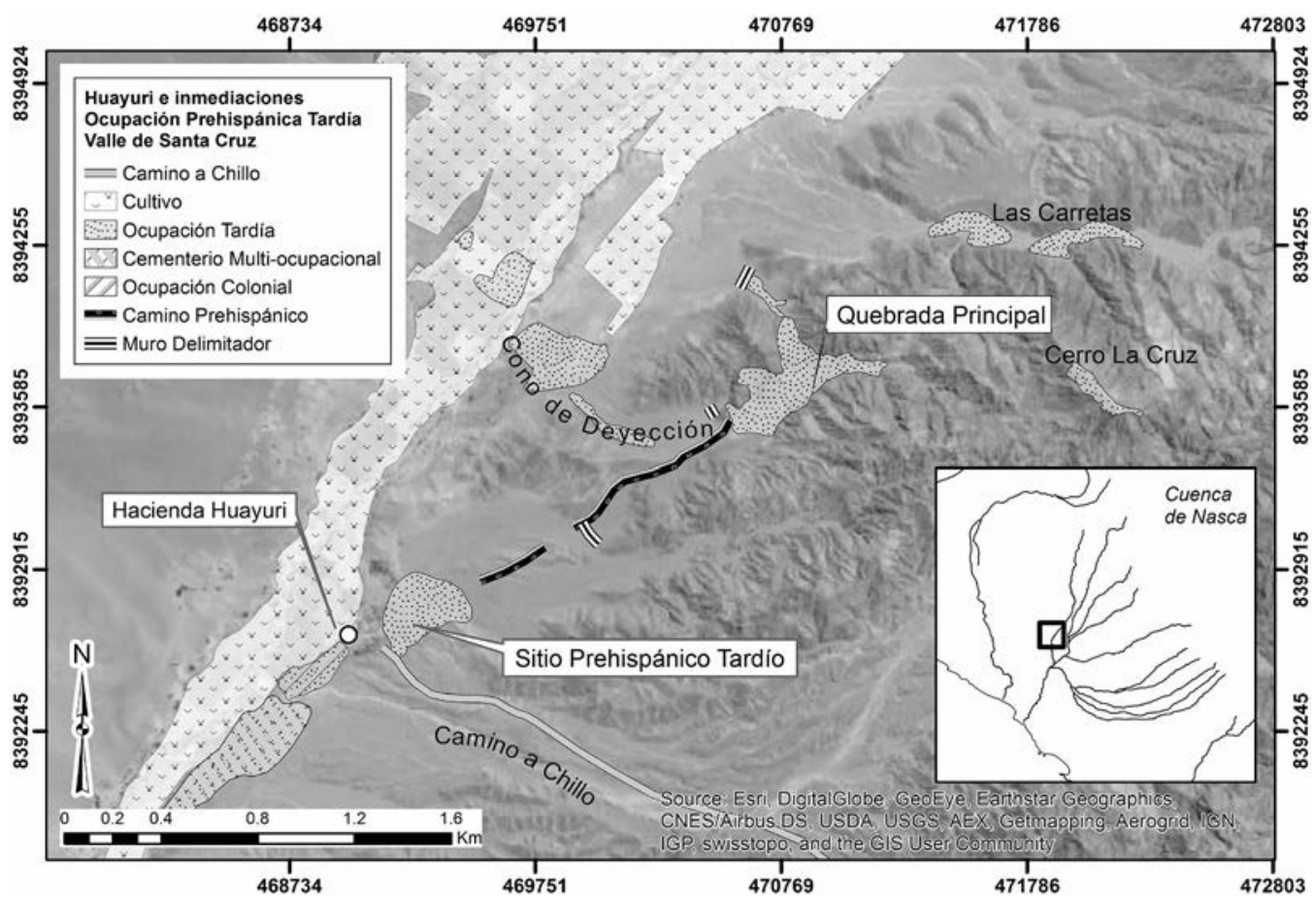

Figura 7. Localización de Huayuri en el valle de Santa Cruz (Sistema de Coordenadas WGS 1984; mapa: Viviana Siveroni basado en imágenes de Esri, Digital Globe, GeoEye, EarthStar Geographics, CNS/AirBus DS, USDA, USDH, AEX, Getmapping, AereoGrid, IGN, IGP, Swisstopo, and the GIS user community).

en 1932. Por otro lado, un conjunto de estructuras de traza de tendencia ortogonal (algunas solo visibles desde el aire por variaciones de colores de los terrenos de cultivo), y un montículo pequeño y posible plaza se vislumbran en el área entre el piso del río y la entrada a la Quebrada Principal de Huayuri (Fig. 7). El fechado de estos dos sitios fuera de la quebrada es tentativo y se basa en el material de superficie que es de manufactura local del Horizonte Tardío y posiblemente del Período Colonial Temprano (Siveroni et al. 2004). Es altamente probable que Huayuri y estos dos sitios descritos funcionaran conjuntamente en un momento.

Es preciso notar que, en la Ordenanza de Tambos de 1543, Vaca de Castro describe a Huayuri como «el primer valle de Lanasca el cual ha de estar siempre poblado el tambo y proveido por razón de que ay dose leguas de despoblado del Tambo (de Ica) a otro en el cual an de servir los indios del mismo valle» (Vaca de Castro 1908 [1543]: 448; el énfasis es mío).

Si Huayuri arqueológico es el pueblo mencionado arriba no es seguro, pero, si fuera así, esto significaría que sus habitantes pagaban mita, como era el caso de muchos de los tambos usados por los españoles antes de las reformas toledanas, en donde los encomenderos continuaron sus vínculos con las poblaciones locales tal cual se daba en tiempos Inca (Glave 1989). Según Margarita Gentile (1977), el camino real (inca) entraba al valle de Huayuri y seguía por Chillo, y la entrada al segmento Chillo empieza en el sitio excavado por Ubbelohde-Doering mencionado arriba. Aun los pobladores locales hablan de este camino que cruza las estribaciones de los cerros conectando la Hacienda de Huayuri con Chillo — ubicado en el vecino valle de Rio Grande (Aldo y Danny Moquillaza, comunicación personal). Las conexiones espaciales exploradas aquí entre Huayuri y estos dos sitios de planta ortogonal sugieren que cualquiera de estos sitios contemporáneos a Huayuri podrían ser los restos del tambo. No nos es posible decir aun con certeza si el tambo mencionado por Vaca de Castro precede a 1543, pero es probable. 


\section{El sitio}

Dentro de la Quebrada Principal, la arquitectura es compacta y aparentemente desordenada, pero con conjuntos de habitaciones organizados en torno a patios rectangulares de tamaños variables, los que muchas veces presentan batanes de piedra de aproximadamente un metro de diametro; calles ondulantes proveen circulación dentro del sitio (Fig. 8). Los dos proyectos arqueológicos que trabajaron aquí anteriormente fechan la ocupación del sitio al Período Intermedio Tardío y Horizonte Tardío por la cerámica asociada (Alfaro de Lanzone 1975; Giuseppe Orefici 1985, 1987).

En este punto de la investigación, no hemos definido ningún rasgo en superficie que indique la existencia de construcciones públicas, áreas cívico-ceremoniales o residencias de alto estatus. Un pequeńo sector en la parte sur del sitio, denominado Conjunto C02, presenta un patrón arquitectónico ligeramente distinto, sugerido por el plan ortogonal. Un estudio más detallado de los restos en superficie que incluye fotos antiguas del sitio podrían en el futuro cambiar esta imagen.

Lo que sí llama la atención son rasgos constructivos que sugieren más bien características corporativas (Carballo 2013). Más allá de su función específica, son notables las murallas descritas (Fig. 7). Aunque de poco volumen relativamente hablando, definitivamente requirieron de la coordinación de varias unidades domésticas y la posible necesidad de liderazgo para su construcción y, por lo tanto, puede considerárseles elementos arquitectónicos corporativos. La evidencia a nivel del asentamiento, entonces, apunta hacia un pueblo de grandes dimensiones, probablemente centro de una sociedad poco jerarquizada, organizada al nivel del pueblo con rasgos de una sociedad corporativa.

\section{Las excavaciones}

Las excavaciones de nuestro proyecto tuvieron lugar dentro de la Quebrada Principal del asentamiento y se centraron en el Conjunto $\mathrm{C} 03$ que se identificó como un posible agrupamiento residencial (Figs. 9 y 10). Estas descubrieron un área total de circa 250 metros cuadrados, incluidos el 50 por ciento del área del patio grande, $\mathrm{Pa} 01$, y el área interna de más 20 de estructuras. Los objetivos de nuestro proyecto fueron los de definir mejor la naturaleza de la organización doméstica en el sitio (Siveroni et al. 2004). El resultado del análisis arquitectónico indica que este conjunto habitacional creció orgánicamente y fue la residencia de tres unidades domésticas pequeñas que, aunque interconectadas espacialmente, eran independientes. La subsistencia era agropastoral y diversificada, pues hay evidencias variadas que indican la agricultura y la crianza de camélidos de carga, así como la producción intensa de textiles y esporádica de cerámica (Siveroni e.p.). La abundancia de los restos de camélidos en otros sectores diferentes al Conjunto Habitacional C03 ha sido también enfatizada por Orefici en sus informes de excavación $(1985,1987)$, del mismo modo que la abundancia de herramientas de hilado y tejido, situación que es comparable a nuestros hallazgos (Siveroni y Tiballi 2016; Siveroni e.p.).

El material recuperado en la excavación sugiere que lo excavado del Conjunto C03 fue ocupado mayoritariamente durante el Horizonte Tardío (Figs. 11 y 12). Encontramos material cerámico que Menzel (1976) asigna a las varias fases estilísticas del estilo Ica 6 al 9/10. Basándonos en los fragmentos de estilo Inca Provincial y a las advertencias planteadas por Sandweiss (1992) a partir de los contextos excavados por él en Lo Demás, pensamos que los niveles excavados en estas residencias de Huayuri funcionaron durante el Horizonte Tardío. La excavación muestra que las estructuras arquitectónicas excavadas fueron montadas en un casco de traza similar, pero más antiguo. Ignoramos la fecha de esta traza anterior. Por otro lado, algunas estructuras del Conjunto C03 pudieron haber continuado en el período de contacto; no obstante, esto es difícil de determinar dada la invisibilidad de marcadores cronológicos en el momento inicial de la invasión española en el área (véase Traslaviña 2016 para una situación similar en el valle de Lurín). En cuanto a este punto, hasta el momento, se han examinado un total de c. 4800 fragmentos cerámicos diagnósticos de forma o decoración, de los cuales solo dos fragmentos muestran posible manufactura mediante torno y, por ende, podrían indicar su uso temporal durante el período de contacto. No existen otros indicadores 


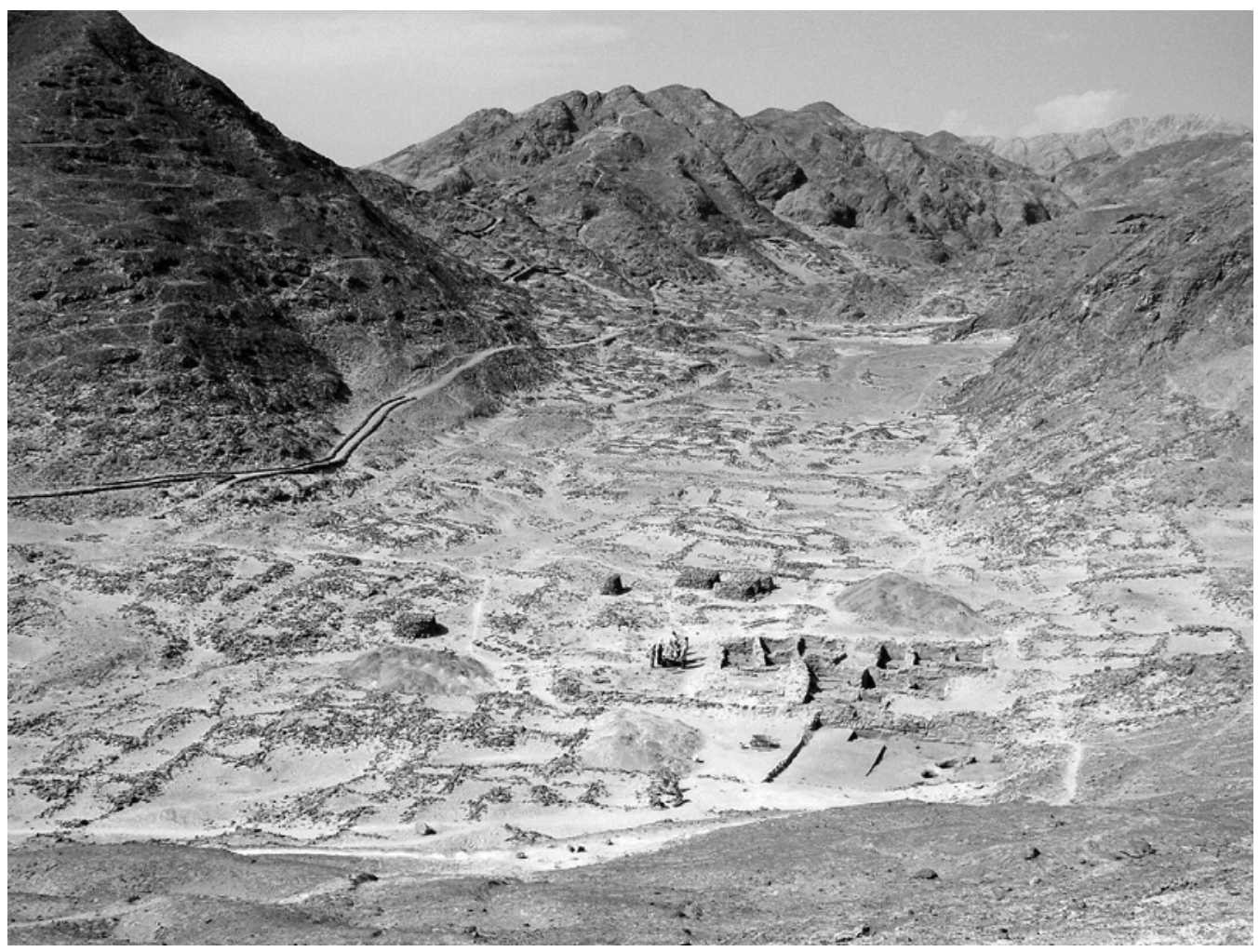

Figura 8. Vista de la Quebrada Principal, Huayuri, con el área excavada en primer plano (vista desde el extremo suroeste) (foto: Viviana Siveroni).

coloniales (como cuentas de vidrio, porcelana y ceramica vidriada). Los proyectos anteriores no reportan indicios de una ocupación de la época de contacto.

\section{Las campanas}

Durante las excavaciones del Conjunto Habitacional C03 de Huayuri, se recuperaron dos tipos de artefactos de función desconocida al momento de la excavación. Posteriormente, estos fragmentos fueron identificados como fragmentos del cuerpo sonoro de campanas cerámicas y de sus badajos, como será evidente después de la descripción siguiente (Fig. 13).

Cuarenta y seis fragmentos que corresponden al vaso sonoro - tanto a su borde como al cuerpo- fueron recuperados de apisonados y rellenos de las viviendas y del patio del Conjunto C03. Todos los ejemplares asignados o identificados como cuerpos sonoros de campanas son, sin embargo, muy pequeños y solo un escaso grupo corresponde a la mitad de un artefacto completo. Durante el proceso mismo de excavación, estos fragmentos llamaron la atención por aparentar ser fragmentos de cuencos esféricos pequeños pero achatados por sus lados y con perforaciones a la altura del «pliegue». Un par de los fragmentos grandes permitieron reconstruir de modo general la forma del cuerpo sonoro. En el caso de este ejemplar, el largo máximo es de 13 centímetros y la altura aproximada de cinco centímetros (Fig. 14). Los fragmentos de borde pertenecientes a la zona del "pliegue» de la campana indican variabilidad formal de las campanas encontradas. Los fragmentos que conservan parte del cuerpo y que incluyen la base muestran que esta fue convexa y la presencia de dos perforaciones precocción hechas en la parte cercana al pliegue y relativamente cerca a la base del «cuenco». El acabado de superficie exterior es similar al que se encuentra en los cuencos 


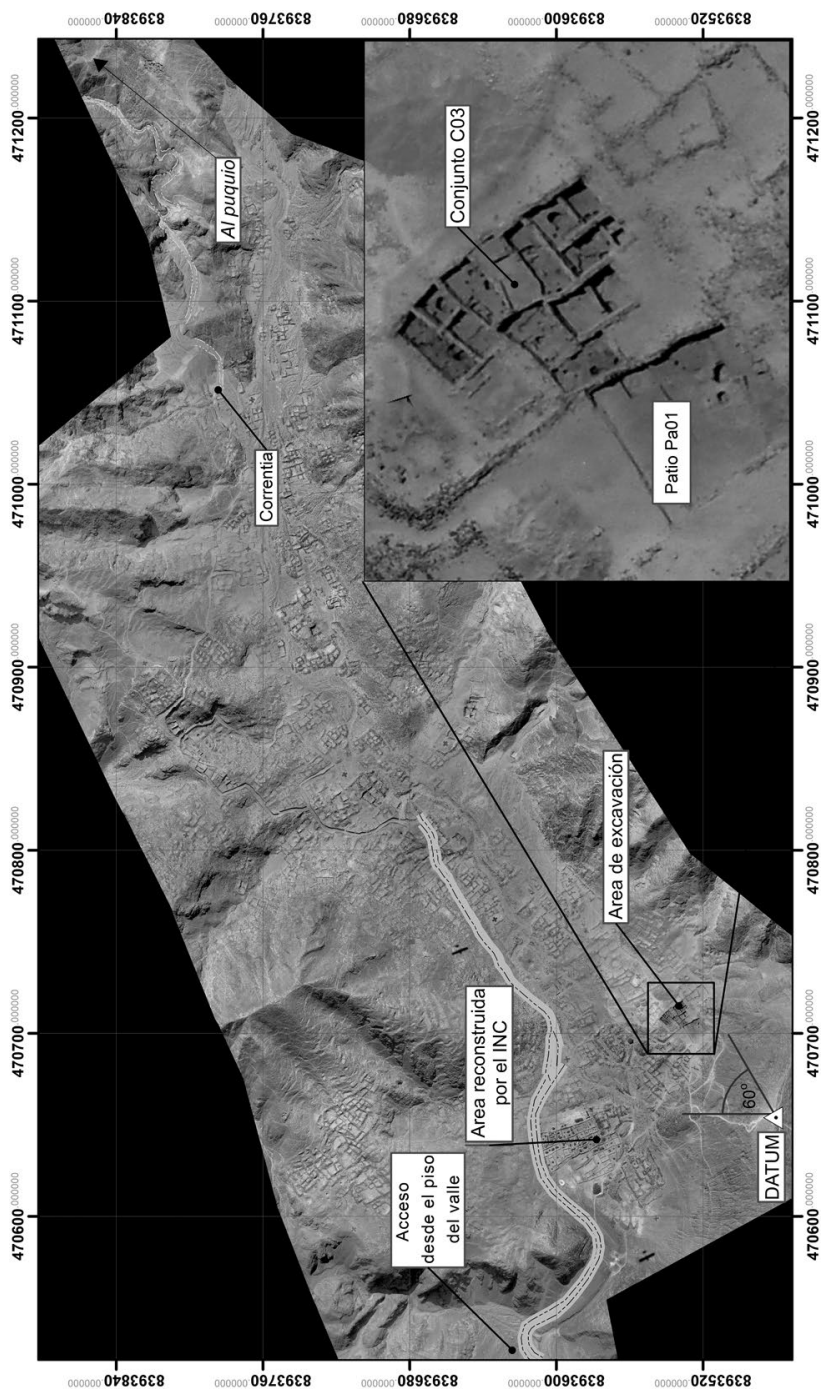

Figura 9. Ubicación del Conjunto CO3 dentro de la Quebrada Principal, Huayuri (Fotos base por Viviana Siveroni, Mosaico base elaborado por Hartmut Tschauner; Sistema de Coordenadas WGS 1984)(diagramación: Viviana Siveroni).

semiesféricos de uso doméstico típicos del estilo Ica, los que Menzel (1976) denomina cumbrous bowls y que son abundantes en el sitio. Como es típico de los cuencos, estas piezas presentan un tratamiento de superficie básico. Predomina un alisado húmedo con estrías que cubre parcialmente las huellas dejadas en la superficie exterior de un posible plato de alfarero o soporte que estuvo en contacto con toda la superficie exterior del recipiente cuando húmedo. Generalmente, presentan una banda de alisado húmedo, como en muchos cuencos de uso doméstico encontrados en el sitio, muchas veces, con estrías a lo largo del borde probablemente causadas por un textil, y quizá el borde tiende a ser adelgazado como consecuencia de este patrón. También, existen casos con superficies externas que han sido alisadas o bruñidas con objetos duros cuando la pasta estuvo en estado al cuero. La superficie interior presenta un alisado que tiende a ser burdo e irregular, y deja entrever las marcas del alisador y raspador. El ripio producto de las perforaciones hechas cuando la pasta está aún húmeda no ha sido removido de la superficie interior, lo cual evidencia la dirección desde la cual estas fueron realizadas. Nuestra reconstrucción de las campanas completas (Fig. 14) —basada en los fragmentos encontrados - sugiere claramente la correspondencia formal con un hallazgo aislado documentado para el valle de Ica por Oliver Whaley (Fig. 15). El ejemplar completo claramente muestra un cuerpo sonoro en forma de cuenco de base convexa. Este ejemplar tiene 13 centímetros 


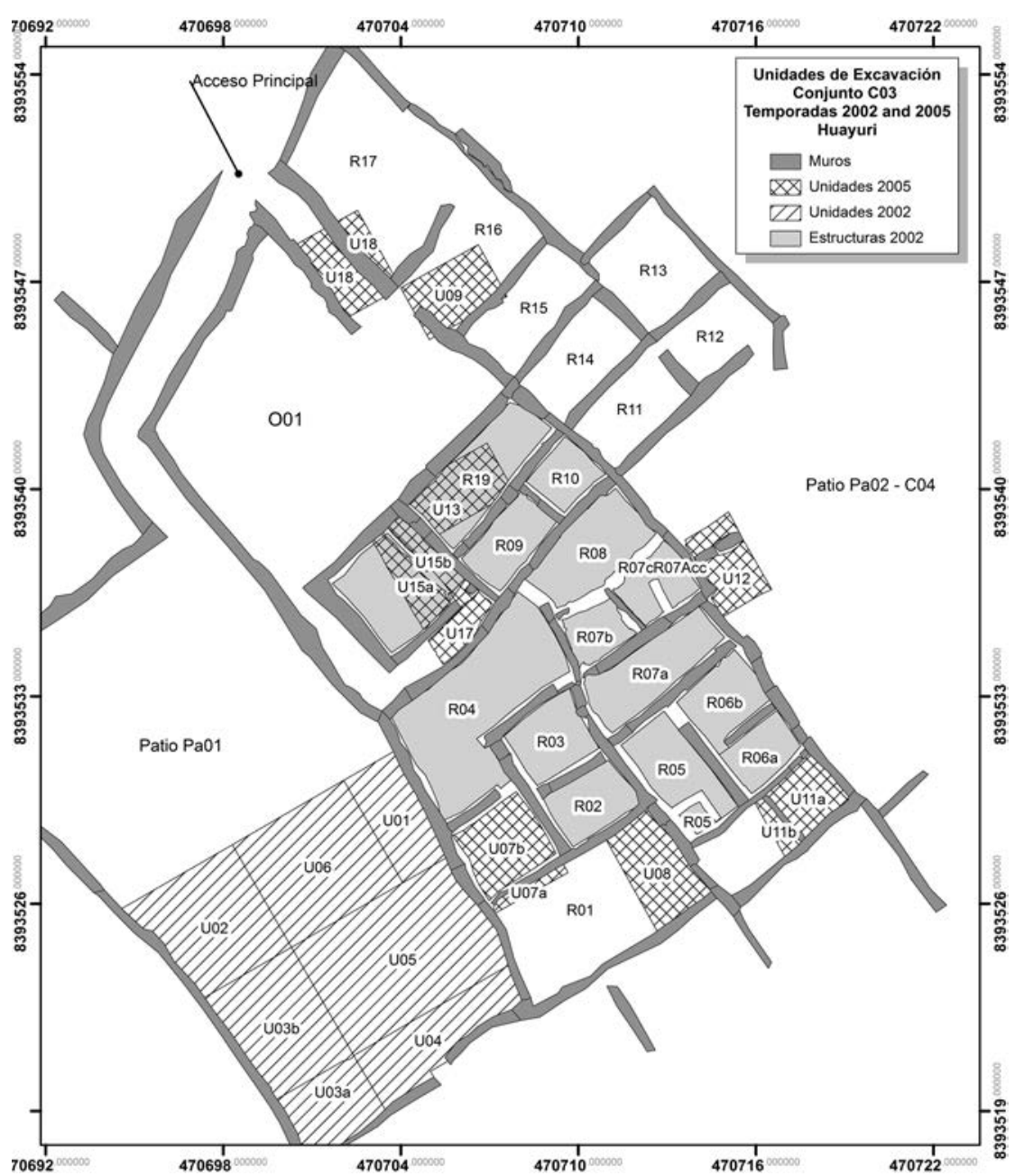

Figura 10. Unidades de excavación dentro del Conjunto C03, Huayuri (Sistema de coordenadas WGS 1984) (dibujo: Viviana Siveroni).

de largo máximo y, aproximadamente, 7 centímetros de altura. Tanto las dimensiones, forma y tratamiento de superficie de este ejemplar completo, así como una comparación con los fragmentos provenientes de Huayuri, muestran que se trata del mismo tipo de artefacto. Además, la forma de estas campanas cerámicas es claramente comparable a los ejemplares metálicos de campanas prehispánicas provenientes de Ica que fueron descritas en la sección anterior (Gudemos 2013).

En cuanto a los badajos de cerámica, encontramos un total de 88 ejemplares; 26 de estos están completos. El largo promedio es de 6,16 centímetros cuando se encuentran completos y su peso promedio de 7,6 gramos (Fig. 16, Tabla 2). Algunos de los ejemplares muestran un alisado húmedo, aunque muchos de los estos solo muestran las huellas dactilares producto del modelar la arcilla cuando aún en estado plástico. Los badajos tienen una perforación precocción, y el otro extremo puede ser ligeramente adelgazado o romo. Aunque la campana de Whaley no fue encontrada con sus badajos, en el contexto presentado aquí, la similitud formal de los badajos de Huayuri con los que presenta Angiograma (2001) sustentan fuertemente su interpretación funcional.

Como se deduce de la proveniencia estratigráfica y espacial indicada, es claro que las campanas y badajos provienen tanto de los apisonados y rellenos de las casas, y del patio adosado (Tabla 1; 

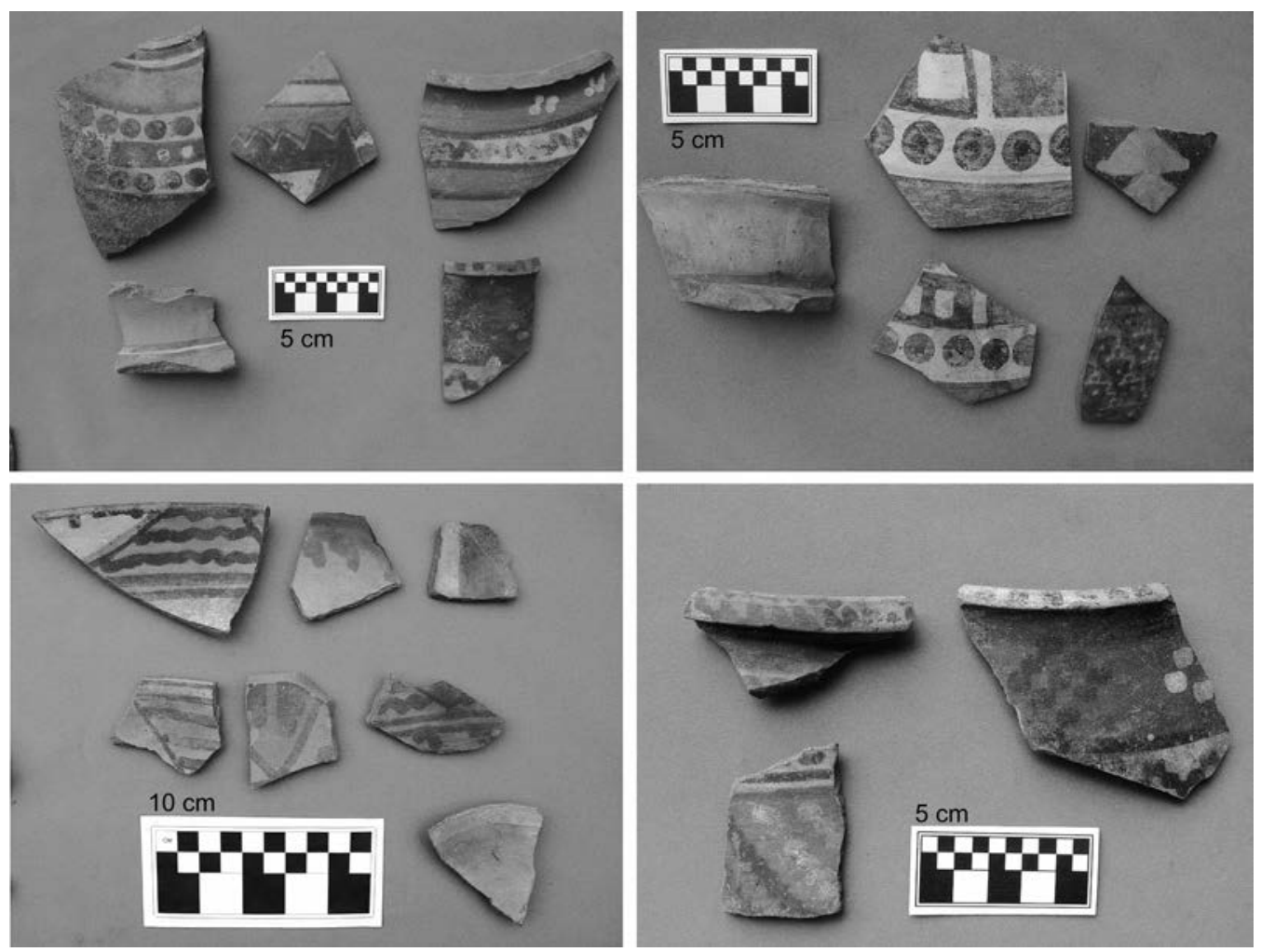

Figura 11. Cerámica recuperada de la excavación del Conjunto CO3, Huayuri: arriba, cántaros y ollas de borde carenado; abajo, cuencos y ollas de cuello carenado (foto: Viviana Siveroni).
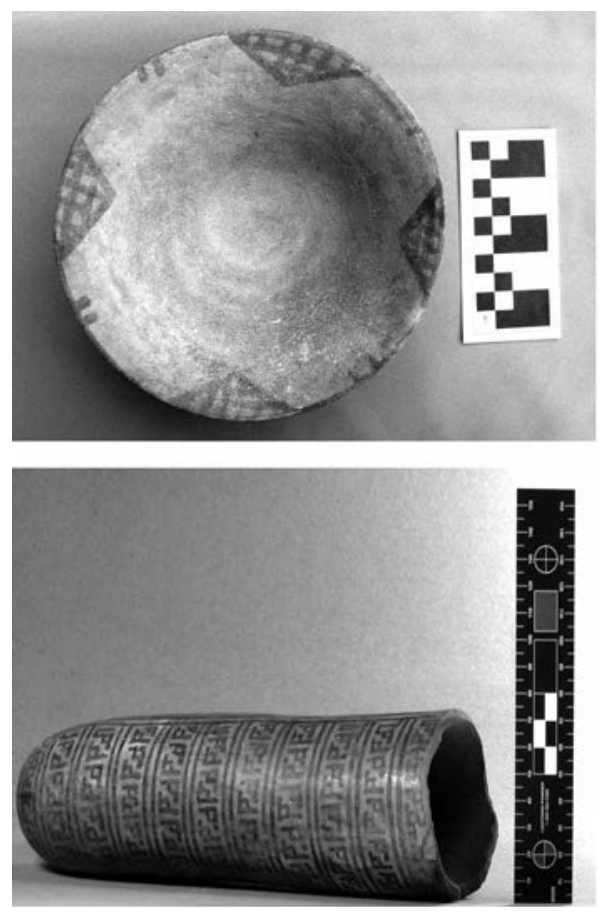

Figura 12. Cerámica recuperada de la excavación del Conjunto CO3, Huayuri: arriba, cuenco de paredes evertidas cóncavas ("Cumbrous bowl", Fase Ica 9/10 según Menzel 1976; escala es $10 \mathrm{~cm}$ ); abajo, vasija fitomorfa fragmentada (escala es $15 \mathrm{~cm}$ ) (foto: Viviana Siveroni). 


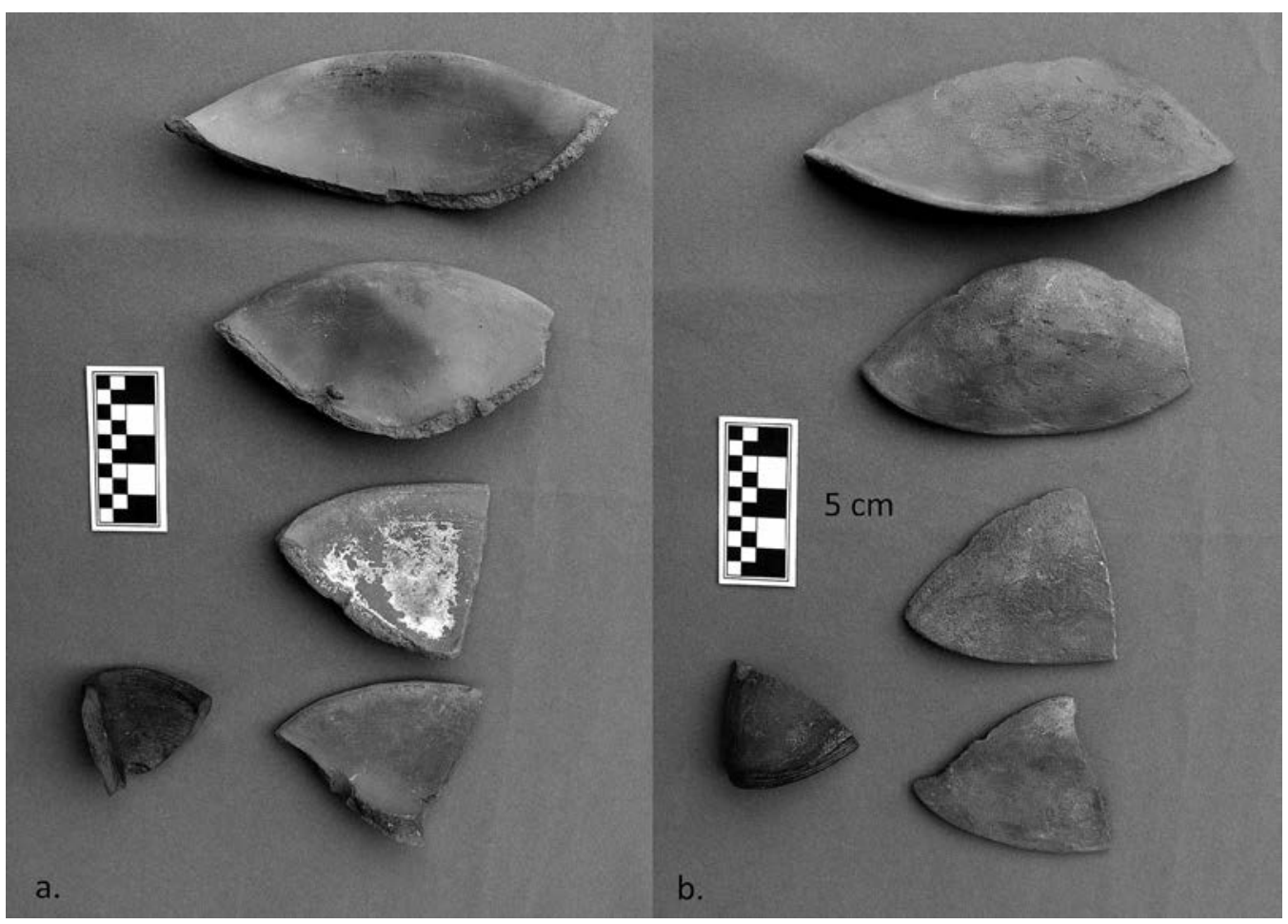

Figura 13. Fragmentos de campanas cerámicas del Conjunto C03, Huayuri: a, Interior; b, Exterior (fragmentos rotados 180 grados) (foto: Viviana Siveroni).
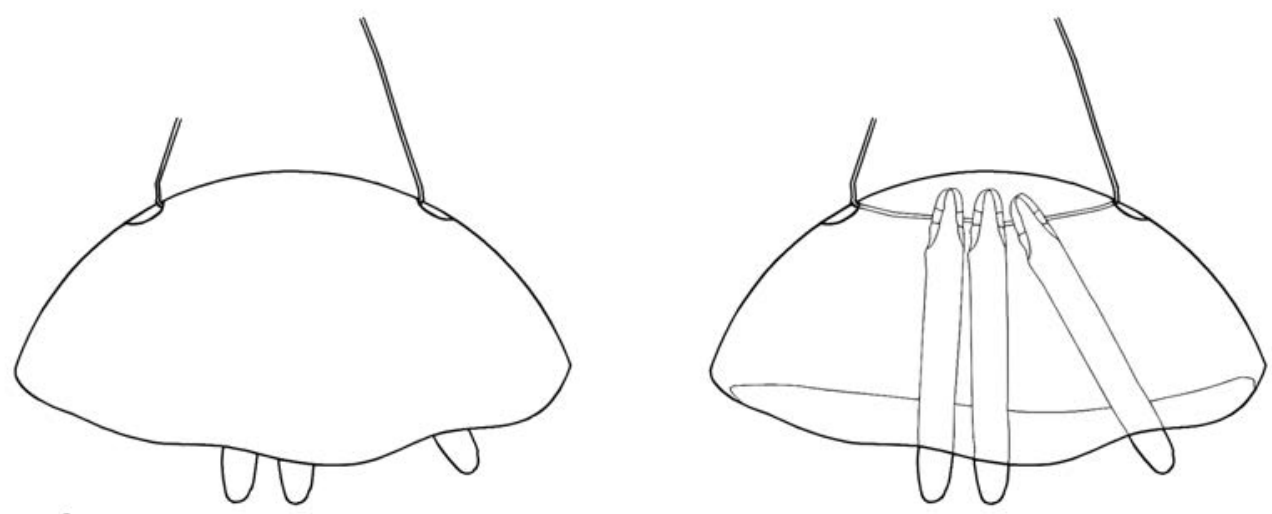

0

$10 \mathrm{~cm}$

Figura 14. Reconstrucción de las campanas cerámicas de Huayuri basada en fragmentos recuperados (dibujo: Viviana Siveroni). 

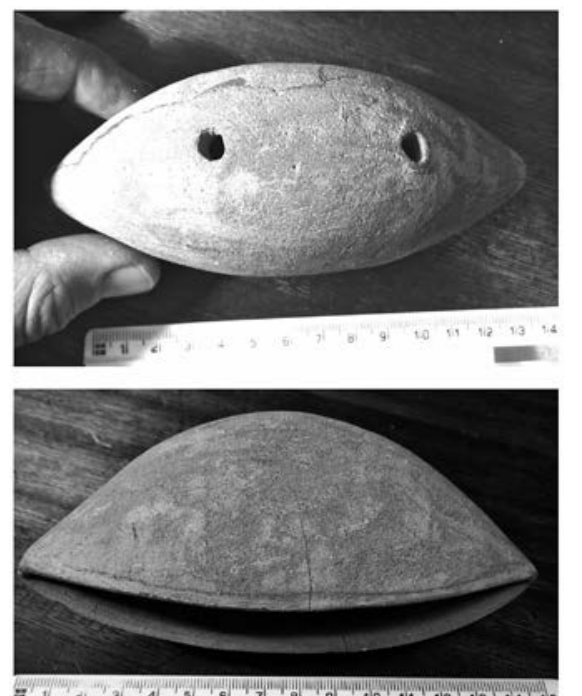

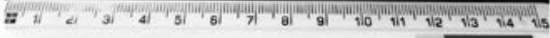

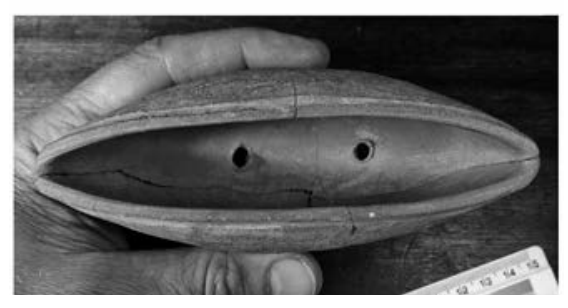

Figura 15. Campana cerámica prehispánica de Zamaca, valle de Ica (fotos: cortesía de Oliver Whaley).

compárese con el mapa de arquitectura de la Fig. 10). En la siguiente sección, describo la naturaleza de los contextos del patio por ser los más relevantes para la construcción de nuestro argumento caravanero.

\section{Las asociaciones del patio}

Los trabajos del 2002 incluyeron la excavación del 50\% del área del patio denominado $\mathrm{Pa} 01$ (Fig. 10). Los patrones de circulación indican que era posible acceder desde el exterior del Conjunto C03 mediante una calle desde el noroeste del patio, pero, además, existía un acceso en la pared noreste que permitía el acceso desde un patio interno del conjunto habitacional (Fig. 10, Unidad U07, Estructura R04). Era posible, además, ingresar a otras áreas domésticas aledañas al Conjunto $\mathrm{C} 03$, aquellas que se adosan a la pared sureste del patio y posiblemente también hacia las viviendas del suroeste. Las excavaciones cerca al muro noreste del patio muestran que la conformación del patio, tal como se la conoce desde la superficie, se da al final de la secuencia constructiva; sin embargo, los restos de las superficies inferiores — que no se asocian al dicho muro- presentan características similares, por lo que sugerimos que su función fue la misma antes y después de la construcción del muro perimetral del patio. Los restos más significativos documentados en el patio son restos de excreciones o coprolitos de camélidos en las superficies; restos de huecos de postes que conforman una ramada paralela al muro noreste del patio; un rasgo cavado en el centro del patio conteniendo mayoritariamente tiestos de vasijas de tamaños variados, coprolitos de camélido y un poste quemado; y una acumulación de basura en la esquina este del patio. Es importante notar que la densidad de coprolitos sobre las superficies fue relativamente baja pero distribuida homogéneamente en toda el área excavada del patio. A pesar de densidad baja, los coprolitos de camélidos se presentan dentro de la mayoría de los huecos de postes registrados en el patio (Fig. 17). 


\begin{tabular}{|c|c|c|}
\hline \multirow{2}{*}{ Unidad de Excavación } & \multicolumn{2}{|c|}{ Total de especímenes } \\
\hline & campanas & badajos \\
\hline $\mathrm{C} 03$ & 2 & 3 \\
\hline O01 & 1 & 1 \\
\hline R02 & & 1 \\
\hline R03 & & 1 \\
\hline R04 & 8 & 6 \\
\hline R05 & 1 & 1 \\
\hline R06 & 2 & 2 \\
\hline R06a & & 4 \\
\hline R06b & & 3 \\
\hline R07 & & 2 \\
\hline $\mathrm{R} 07 \mathrm{a}$ & 5 & 15 \\
\hline R07b & 1 & 4 \\
\hline R07cR07Acc & & 2 \\
\hline R08 & 5 & 4 \\
\hline R09 & 1 & \\
\hline R19 & 1 & 12 \\
\hline U01 & 1 & \\
\hline U02 & 2 & 1 \\
\hline U03 & 2 & 4 \\
\hline U04 & 4 & 4 \\
\hline U05 & 4 & 1 \\
\hline U06 & 1 & 4 \\
\hline U07b & & 2 \\
\hline U09 & 1 & 1 \\
\hline U11 & 1 & 1 \\
\hline U11a & & 2 \\
\hline U12 & & 3 \\
\hline U13 & & 2 \\
\hline U15 & 2 & 1 \\
\hline U17 & 1 & 1 \\
\hline Total & & 88 \\
\hline
\end{tabular}

Nota.- La muestra incluye badajos completos y fragmentados

Tabla 1. Distribución espacial de campanas y badajos recuperados de la excavación, Conjunto C03, Huayuri. 


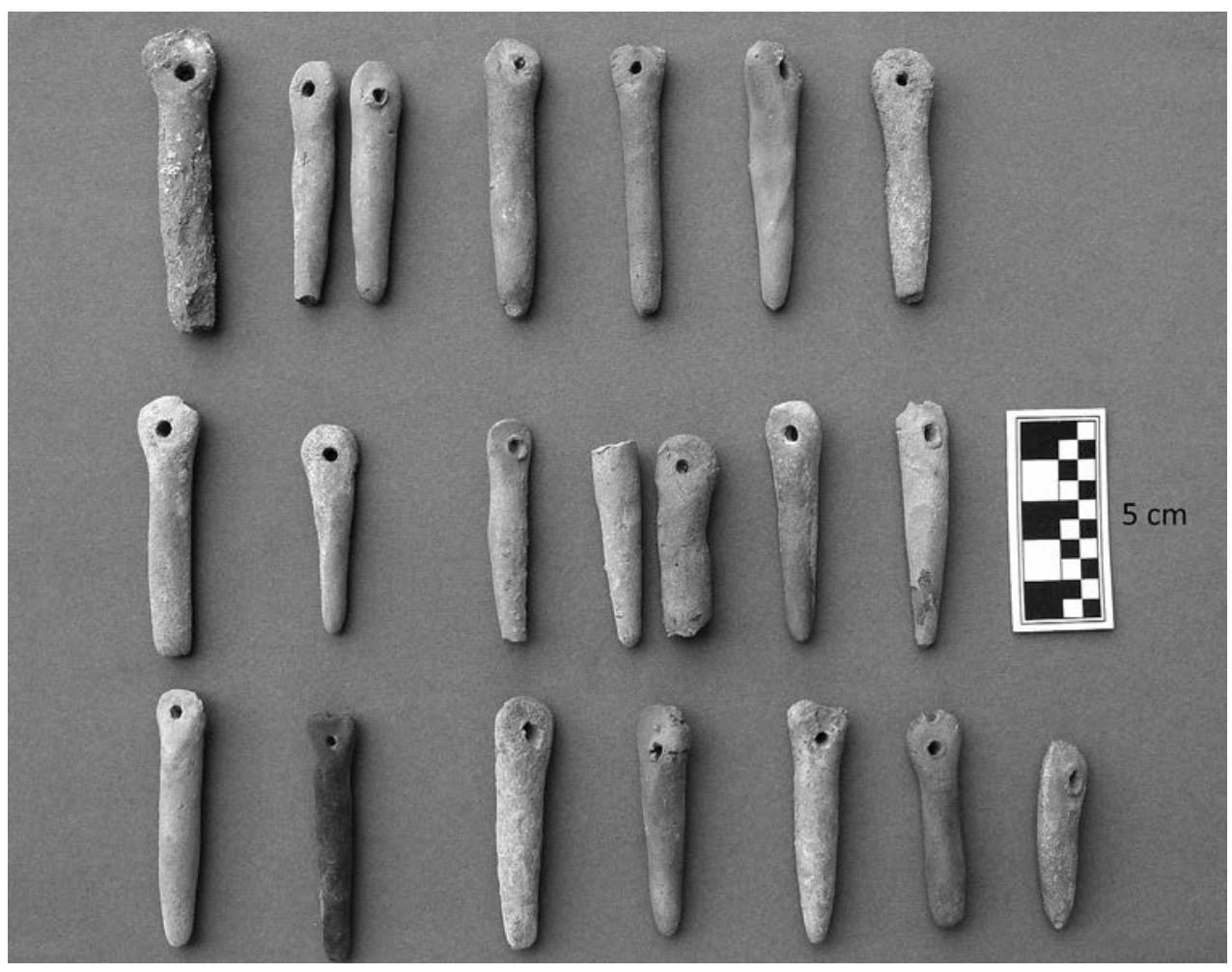

Figura 16. Badajos de cerámica del Conjunto C03, Huayuri (foto: Viviana Siveroni).

Por último, la estratigrafía de la esquina este del patio demuestra que el basural se formó a lo largo del tiempo, antes de la construcción del muro, pero que continuó luego de la reestructuración espacial del patio. La textura de las capas de basural indica que fue usado de apisonado, que se constituyó como una rampa informal para acceder al área doméstica al sureste del patio.

El contenido de este basural es bastante informativo. Encontramos, entre varias cosas, restos de deshechos textiles, restos macrobotánicos y material óseo. Un análisis preliminar de una muestra pequeña del material faunístico indica que el componente más común son los especímenes óseos de camélido. En particular, la distribución de partes anatómicas de los huesos de camélido muestra que la mayoría de las partes del animal estuvieron presentes en el sitio (Fig. 18) y sugiere que los restos de camélidos fueron sacrificados in situ ${ }^{1 .}$

\section{Discusión}

En la sección precedente, he descrito las características morfológicas de los ejemplares de campanas y badajos cerámicos encontrados en el Conjunto Habitacional C03 de Huayuri, un sitio del Horizonte Tardío en la quebrada de Huayuri, área de Nasca. Además, he presentado la naturaleza del contexto arqueológico en el que estos artefactos fueron encontrados poniendo énfasis en los hallazgos del patio, pues son los más relevantes para sostener el argumento caravanero.

Los rasgos formales de los ejemplares encontrados indican que las campanas cerámicas de Huayuri son pequeños cuerpos sonoros, que se asemejan a pequeños cuencos semiesféricos aplastados en los lados. Estos cuerpos sonoros semiesféricos estaban provistos de dos perforaciones. Haciendo una comparación con los ejemplos de campanas arqueológicas encontrados en la literatura y descritas anteriormente, es evidente que estos orificios se usaron tanto para sujetar los badajos 


\begin{tabular}{|l|c|c|c|c|}
\hline \multirow{2}{*}{ Badajos completos } & Largo & Peso & $\begin{array}{c}\text { Ancho a la altura } \\
\text { del orificio }\end{array}$ & $\begin{array}{c}\text { Diámetro medio } \\
\text { del cuerpo }\end{array}$ \\
\cline { 2 - 5 } & {$[\mathrm{cm}]$} & {$[\mathrm{gr}]$} & {$[\mathrm{cm}]$} & {$[\mathrm{cm}]$} \\
\hline Rango & 2.83 & 10.1 & 1.38 & 1.66 \\
\hline Valor mínimo & 4.8 & 4.1 & 0.45 & 0.02 \\
\hline Valor máximo & 7.63 & 14.2 & 1.83 & 1.68 \\
\hline Media & 6.159 & 7.596 & 1.417 & 0.989 \\
\hline Desviación estándar & 0.612 & 2.157 & 0.249 & 0.333 \\
\hline Sesgo & -0.065 & 1.167 & -2.301 & -1.3 \\
\hline Error estándar & 0.456 & 0.456 & 0.456 & 0.456 \\
\hline Nota-- n=26 & & & & \\
\hline
\end{tabular}

Tabla 2. Estadisticas descriptivas de los badajos completos de Huayuri.

dentro del cuerpo sonoro - posiblemente, mediante cuerdas o tiras de cuero- como para colgar las campanas de algún medio externo.

Adicionalmente, los datos presentados por Gudemos $(1998,2013)$ de campanas metálicas provenientes de Ica y fechados relativamente al Período Intermedio Tardío sitúan las campanas cerámicas de Huayuri en un contexto más amplio. En primer lugar, las campanas metálicas establecen un referente morfocultural e insertan esta categoría funcional en el repertorio material producido y usado por las poblaciones tardías de la costa sur, particularmente, de Nasca e Ica. No existen casos de campanas cerámicas (ni de sus badajos) reportados como tales en la literatura arqueológica de Ica o Nasca. Sin embargo, la razón de esta aparente ausencia puede deberse en parte al hecho de que los fragmentos de campanas pueden ser confundidos fácilmente con cuencos semiesféricos pequeños mal hechos. Dicho esto, hemos encontrado, además de la campana reportada por Whaley (ver arriba), algunos reportes de «objetos de función desconocida» en algunas publicaciones que pueden ser clasificados o como campanas o como badajos. En cuanto a campanas, encontramos un caso reportado por Menzel proveniente de las tumbas de Tacaraca excavadas por Uhle; dicho caso es descrito como "plain pottery of unknown function», «shell-shaped» (1976: 249). Esta descripción sugiere que el objeto de función desconocida es una campana cerámica. En cuanto a badajos, encontramos dos referencias en informes de investigaciones arqueológicas que ilustran badajos de cerámica descritos como «objetos de función desconocida». El primero proviene del Sitio 220, un asentamiento aglutinado de 20 hectáreas en el valle del Ingenio, reportado por Rubén García (Silverman 1991), y el segundo es proveniente del sitio de Tacaraca en Ica (Mallco 2012: fig. 21) (Fig. 6), evidentemente vinculado al cementerio excavado por Uhle y mencionado en la cita de Menzel (1976) transcrita arriba. Estas referencias añaden más casos de ejemplares de campanas en otros contextos fuera de Huayuri, todos estos del Período Prehispánico Tardío y asociados al estilo Ica. En este contexto, es sugerente que la «Llama Cósmica» del textil Nasca Temprano de Brooklyn lleve una campana que cuelga del cuello (Harcourt 1974: Lámina 97, figs. 50-51).

Los ejemplos comparativos de campanas arqueológicas provenientes de otras áreas y regiones también ponen de manifiesto que existen artefactos de función similar de contextos prehispánicos hechos en cobre y bronce. Es más, esta observación subraya la estrecha conexión entre caravanas y campanas en los casos arqueológicos citados. Debemos recordar al lector los casos arqueológicos del norte de Chile, en donde las poblaciones caravaneras usaban campanas o cencerros en sus llamas, las que son comparables a los casos encontrados en Perú. Hay que notar que el tráfico caravanero del norte de Chile circuló en una franja longitudinal desde Arica hasta el sur del desierto 


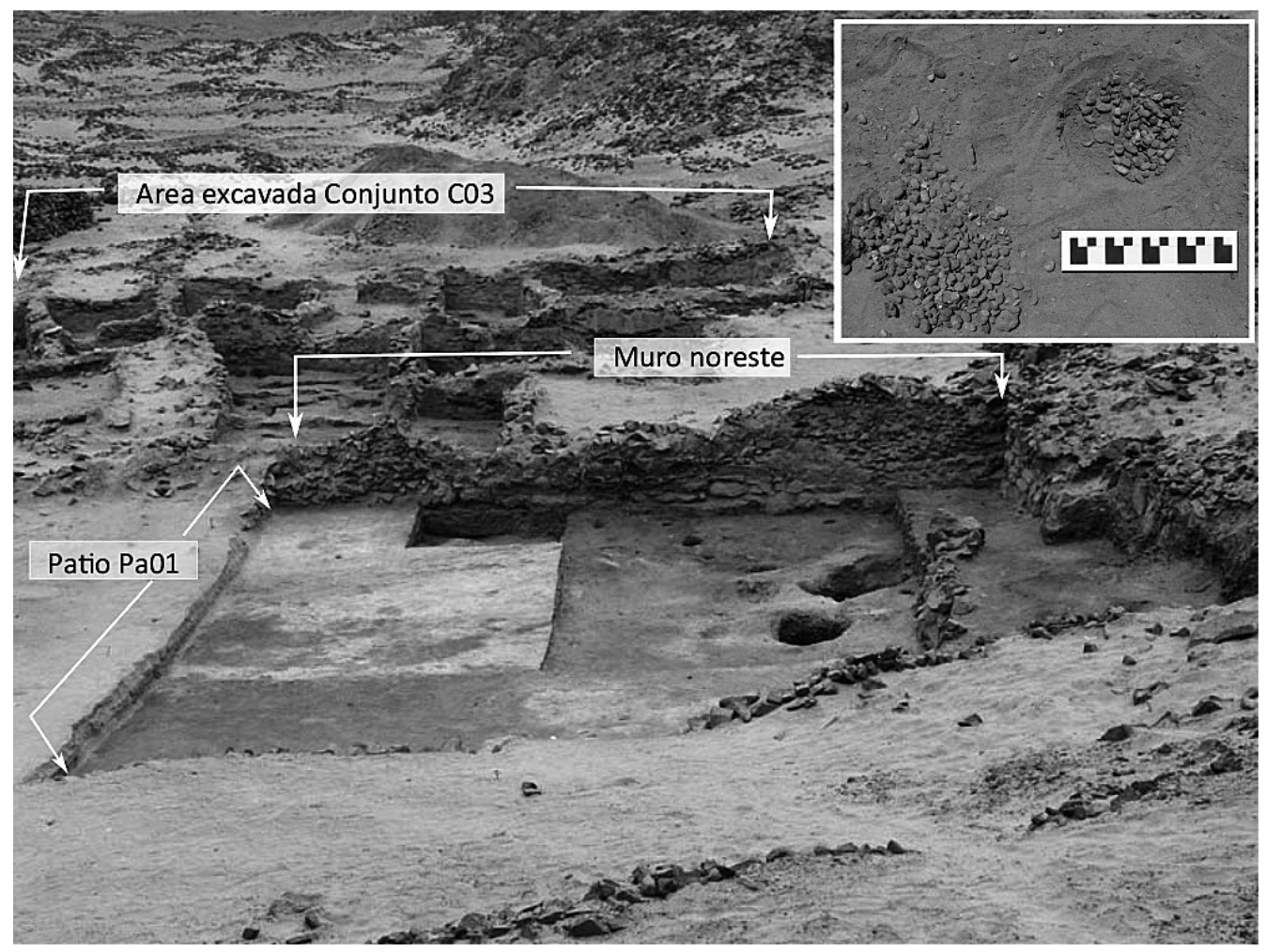

Figura 17. Vista general (desde el oeste) y detalle de coprolitos de camélido en relleno de hueco de poste, Patio Pa01, Huayuri (fotos: Viviana Siveroni).

de Atacama. En el contexto prehispánico en que las fronteras modernas no existían, cabe preguntarse si este intercambio influenció de alguna manera el intercambio caravanero de la costa peruana prehispánica. Los hallazgos de Estuquiña (Clark 1993) de campanas de madera que se asocian a poblaciones criadoras de camélidos son un buen punto (Wheeler 2006; Lozada et al. 2009).

Es interesante notar que, en el caso particular de llameros contemporáneos, es común observar que estas campanas o cencerros son hechos de metal. El lector podría haberse adelantado a asignar un origen colonial a los cencerros en los Andes, pues estas campanas son de cobre, hierro o latón. Sin embargo, debemos enfatizar la implicancia de los hallazgos de Gudemos (2013), a partir de los cuales queda evidenciado un precedente del uso del metal en la manufactura de estas campanas sea en el norte de Chile o en Perú. Es aquí imprescindible mencionar el ejemplar de oro proveniente de Nasca, que, formalmente, es casi idéntico a los cencerros de metal de la tradición trasandina y de madera del norte de Chile y noroeste argentino. Sería aventurado en este estado de la investigación comentar sobre la exacta naturaleza del tipo de contacto, mecanismo de transmisión o producción de material cultural que subyace a la distribución de campanas de metal, cerámica y madera en la costa sur del Perú. No obstante, el parecido formal es sugerente. Más aun, cabría proponer, a modo de hipótesis complementaria, que las campanas coloniales de llameros-directamente conectadas a las observadas en el presente etnográfico - son el resultado de una reinterpretación hecha por los grupos caravaneros de la colonia temprana — y no una imposición occidental— facilitada por la fuerte conexión que hubo entre trajinantes, llamas y centros mineros en el Período Colonial Temprano (Glave 1989).

Además de la analogía etnográfica, la cual provee un modelo para interpretar el rol socioeconómico de estas campanas en Nasca y en Huayuri, existen otras líneas de evidencia independiente que ayudan a sustentar un vínculo entre las campanas de Huayuri y las caravanas de llamas. 


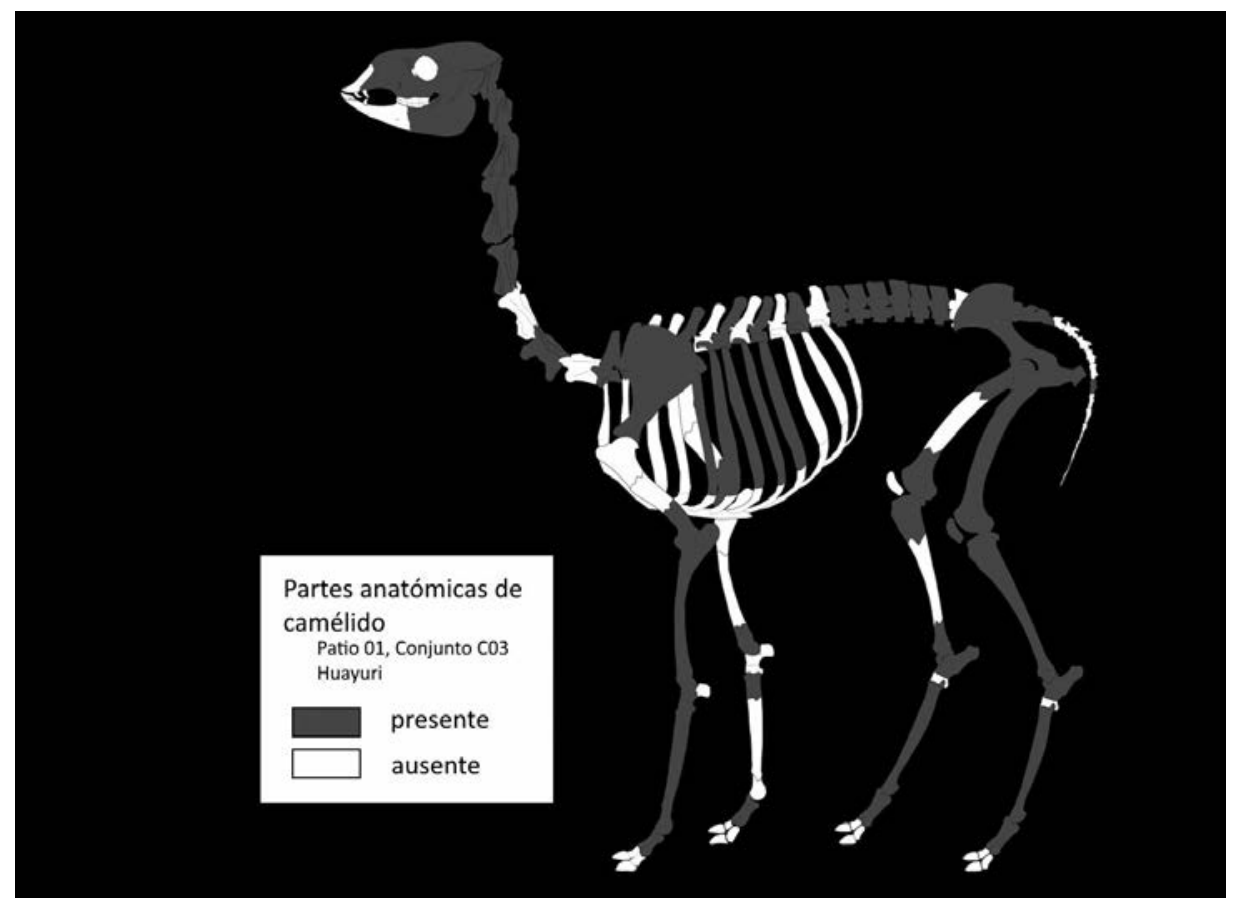

Figura 18. Partes anatómicas de camélido presentes en la muestra preliminar proveniente del basural en la esquina sureste del Patio Pa01, Huayuri (NEI = 212; análisis preliminar a cargo del arqueólogo Luis Pezo) (dibujo: Viviana Siveroni).

La primera línea de evidencia la constituye la existencia del patio mismo, así como sus contenidos, todo lo cual sugiere su uso como corral. Primero, los coprolitos en las superficies excavadas sugieren la presencia de camélidos in situ, y su densidad sugiere un rebaño pequeño o la limpieza cíclica del espacio, o ambos. El rasgo presente en el centro del patio propone que estos episodios de limpieza tuvieron lugar. Además, los coprolitos dentro de los huecos de postes — que formaron parte de una ramada - indican claramente que los postes de esta estructura estaban rodeados de este material antes de ser removidos de su lugar. La ramada misma podría haberse usando, entre otras cosas, para la protección de los animales, tal cual se observa en los casos citados por Nielsen (2001) y Göbel (2002), y en la misma localidad en el presente. Adicionalmente, y siguiendo a Nielsen (2001), los cencerros estarían señalando la residencia de caravaneros.

La segunda línea de evidencia está dada por la distribución de las partes anatómicas de camélidos reflejada por la muestra de huesos de fauna de Huayuri. El análisis da cuenta de la presencia de todas las partes anatómicas del animal en el sitio y sugiere un patrón de autoconsumo (Wapnish y Hesse 1988), común en caravaneros (v.g. Tomka 1994). Una vez incrementada la muestra analizada, tendremos datos sobre la mortalidad del rebaño, importante para determinar el modo de explotación.

Existen otros elementos del registro arqueológico - como las sogas hechas con un mayor componente de lana, conchas marinas con pigmentos, ocarinas en forma de llama y plumas de colores-, todos estos descritos en las etnografías como constituyentes de atados rituales, que, en su conjunto, complementan y dan un mayor sustento al argumento caravanero en Huayuri (Siveroni y Avila Peltroche 2016); no obstante, por falta de espacio, no pueden ser presentados en este artículo.

Finalmente, las campanas cerámicas y los datos sobre su contexto sugieren que estamos ante un caso de caravaneros que vivieron en Huayuri, un asentamiento prehispánico tardío en el área 
de Nasca. No podemos dejar mencionar, aunque sea de manera breve, la información proveniente de una visita al valle de Acari (Fig. 6), una tasa de 1580, que indica la presencia de residentes de Nasca en Arequipa para esas épocas (Espinoza Soriano 1976). El análisis planteado por Waldemar Espinoza saca a relucir que la principal actividad económica de las poblaciones de Nasca que residían en Arequipa era la de caravaneros y argumenta que su presencia en Nasca data de épocas prehispánicas.

\section{Conclusiones}

Las campanas cerámicas encontradas en Huayuri y recuperadas de niveles del Horizonte Tardío encuentran un correlato formal en campanas de metal, de bronce y cobre, reportadas previamente en el valle de Ica. La revisión de la literatura indica que, aunque escasos, existen otros casos de campanas de cerámica, o de sus badajos, reportados en los valles de Ica y Nasca. Un registro más detallado de fragmentos de cerámica que aparentan ser de cuencos semiesféricos mal hechos o de artefactos de «función desconocida» similares a agujas de punta roma que tome las descripciones hechas aquí como punto de partida podrían revelar en el futuro más casos de campanas cerámicas, particularmente, en contextos prehispánicos tardíos de Ica o Nasca.

Una vez identificados estos fragmentos como fragmentos de campanas cerámicas, el argumento principal de este artículo ha sido el de sustentar la presencia de caravaneros o llameros en Huayuri, un sitio ubicado en el desierto de la costa sur peruana. El punto de partida del argumento ha sido el vínculo evidente entre campanas y caravaneros que se reporta en trabajos etnográficos en los que se describen las costumbres y las posesiones de caravaneros contemporáneos que vivieron en Perú, Chile y Bolivia. Adicionalmente, el argumento hace uso de la misma relación campanas/ caravaneros, la cual es evidente en casos prehispánicos, especialmente, en aquellos reportados para el Período Intermedio Tardío del norte de Chile. Estas dos líneas de argumentación se usan para sugerir que las campanas de Huayuri sirvieron como cencerros de llamas. La idea se complementa con evidencias contextuales, tales como la presencia de un posible corral doméstico en Huayuri y los patrones de distribución de partes anatómicas de camélidos, que se dirigen a sustentar la idea de la crianza de camélidos in situ. Mientras que la asignación funcional de los fragmentos de cerámica como campanas es directa, el siguiente eslabón del argumento, su función como cencerros, requiere de mayor sustento. Es necesario ampliar la muestra de casos en los que estas campanas cerámicas aparecen para entender mejor su contexto de uso. Por el momento, la evidencia a la mano es limitada. Por otro lado, es necesario ampliar los análisis óseos para entender mejor los patrones de consumo y utilización para evaluar con mayor precisión el rol de los camélidos en la sociedad tardía de Nasca. Finalmente, serían necesarios análisis isotópicos para incrementar nuestro entendimiento sobre la dieta y lugar de origen de los rebaños. Dicho esto, las campanas de Huayuri y su contexto arqueológico, las campanas de Ica, así como la información proporcionada por la Visita de Acari (Espinoza Soriano 1976) nos sugieren que los asentamientos densamente poblados del Período Prehispánico Tardío de Nasca estuvieron imbuidos en una geografía socioeconómica integrada por redes de intercambio, cuyo eje troncal más visible fue de norte a sur, a lo largo de la costa, un patrón de circulación poco discutido en la literatura pertinente al tema del intercambio mediante caravanas llameras. La naturaleza y la escala de este intercambio son temas que van más allá de los objetivos de este artículo, pero podemos mencionar que las informaciones etnohistóricas citadas indican que los habitantes de Huayuri abastecían al tambo inca del valle y, por tanto, es posible que hayan provisto al tambo con animales de carga. Estos temas se vienen investigando y serán publicados en el futuro.

\section{Notas}

${ }^{1}$ Se agradece a Luis Pezo Lanfranco por haber realizado este análisis parcial de la colección ósea. 


\section{REFERENCIAS}

\section{Alfaro de Lanzone, $\mathrm{L}$.}

1975 Informe de la segunda temporada de excavaciones en la Ciudad Perdida de Huayurí, informe presentado al Instituto Nacional de Cultura, Lima.

Ambrosetti, J. B.

1902 Antigüedades calchaquíes: Datos arqueológicos sobre la provincia de Jujuy, Anales de la Sociedad Cientifica Argentina LIII, 6-96, Coni hermanos, Buenos Aires.

Angiorama, C.

2001 De metales, minerales y yacimientos: Contribución al estudio de la metalurgia prehispánica en el extremo noroccidental de Argentina, Estudios Atacameños 21, 63-88. https://doi.org/10.22199/ S07181043.2001.0021.00004

\section{Berenguer, J. A.}

2002 Tráfico de caravanas, interacción interregional y cambio cultural en la Prehistoria Tardía del desierto de Atacama. tesis de doctorado, Department of Anthropology, University of Illinois at Urbana-Champaign, Urbana.

\section{Boman, E.}

1908 Antiquitiés de la région andine de la République Argentine et du désert d'Atacama, vol. II, Imprimerie nationale, París.

\section{Bonacic, C. y W. L. Franklin}

2007 Camels and llamas, The encyclopedia of mammals [Online] (edición de D. W. Macdonald), Oxford University Press, Oxford.

Bonavia, D.

2008 The South American camelids (edición expandida y corregida de Cotsen Institute of Archaeology), University of California, Los Angeles.

\section{Briones, L., L. Núńez y V. Standen}

2005 Geoglifos y tráfico prehispánico de caravanas de llamas en el desierto de Atacama (Norte de Chile), Chungara 37 (2), 195-223. https://doi.org/10.4067/S0717-73562005000200007

Browne, D.

1992 Further archaeological reconaissance in the Province of Palpa, Department of Ica, Peru, en: N. J. Saunders (ed.), Ancient America: contributions to New World archaeology, 77-116, Monograph no. 24, BAR, Oxbow, Oxford.

\section{Browne, D. y J. P. Baraybar}

1988 An archaeological reconaissance in the Province of Palpa, Department of Ica, Peru, en: N. J. Saunders y O. de Montmollin (eds.), Recent studies in pre-Columbian archaeology, 299-325, BAR International Series, vol. 421, Oxford.

Carballo, D. M.

2013 Labor collectives and group cooperation in pre-Hispanic Central Mexico, en: . M. Carballo (ed.), Cooperation and collective action, 243-274, Archaeological Perspectives, University Press of Colorado, Boulder.

Clark, N. R.

1993 The Estuquiña textile tradition: cultural patterning in Late Prehistoric fabrics Moquegua, far southern Peru, tesis de doctorado, Department of Anthropology, Washington University of St. Louis, Missouri.

Conlee, C.

2000 Late prehispanic occupation of Pajonal Alto, Nasca, Peru: implications for imperial collapse and societal reformation, tesis de doctorado, Department of Anthropology, University of California, Santa Barbara.

2003 Local elites and the reformation of Late Intermediate Period socioeconomical and economic organization in Nasca, Peru, Latin American Antiquity 14 (1), 47-65. https://doi.org/10.2307/972235

2004 The expansion, diversification, and segmentation of power in Late Prehispanic Nasca, Archeological Papers of the American Anthropological Association 14 (1), 211-223. https://doi.org/10.1525/ap3a.2004.14.211 


\section{Conlee, C. y K. Schreiber}

2006 The role of intermediate elites in the balkanization and reformation of post-Wari cociety in Nasca, Peru, en: C. M. Elson y R. A. Covey (eds.), Intermediate elites in pre-Columbian states and empires, University of Arizona Press, Tucson.

Covey, R. A.

2008 Multiregional perspectives on the archaeology of the Andes during the Late Intermediate Period (c. A. D. 1000-1400), Journal of Archaeological Research 16 (3), 287-338. https://doi.org/10.1007/s10814-008$9021-7$

Dransart, $P$.

1991 Llamas, herders and the exploitation of raw materials in the Atacama desert, World Archaeology 22 (3), 304-319. https://doi.org/10.1080/00438243.1991.9980148

2011 Social principles of Andean camelid pastoralism and Archaeological interpretations, en: U. Albarella y A.Trentacoste (eds.), Ethnzooarchaeology: the present and past of human-animal relationships, 123-130, Oxbow, Oxford.

Dulanto, J.

2008 Between horizons: diverse configurations of society and power in the Late Pre-Hispanic Central Andes, en: H. Silverman y W. H. Isbell (eds.), Handbook of South American archaeology, 761-782, Springer, New York/London. https://doi.org/10.1007/978-0-387-74907-5_38

Eitel, B. y B. Mächtel

2009 Man and environment in the eastern Atacama Desert (Southern Peru): Holocene climate changes and their Impact on pre-Columbian cultures, en: M. Reindel y G. A. Wagner (eds.), New technologies for archaeology: multidisciplinary investigations in Palpa and Nasca, Peru, Springer, Berlín. https://doi. org/10.1007/978-3-540-87438-6_2

Espinoza Soriano, W.

1976 Los mitmas de Nasca en Ocona, Vitor y Camana: siglo XV y XVI; una tasa inédita de 1580 para la etnohistoria andina, Bulletin Del'institut Francias D'etudes Andines 5 (1-2), 85-95.

Flores Ochoa, J. A.

1974 Enqa, enqaychu illa y khuya rumi: aspectos mágico-religiosos entre pastores, Journal de la Société des Américanistes 63 (1), 245-262. https://doi.org/10.3406/jsa.1974.2129

1983 Pastoreo de llamas y alpacas en los andes -balance bibliográfico, Revista Andina 1 (Septiembre), 175-218.

Flores Ochoa, J. A. y A. M. Fries

1989 Puna, qheswa, yunga: El hombre y su medio en Q'ero, Colecciones andinas, Fondo Editorial del Banco Central de Reserva del Perú, Lima.

Flores Ochoa, J. A., K. MacQuarrie y J. Portus

1994 Oro de los Andes: las llamas, alpacas, vicunas y guanacos de sudamerica, Jordi Blasi, Barcelona.

Gentile Lafaille, M.

1977 Informe sobre la ocupación española del valle del Río Santa Cruz (Dpto. de Ica), Siglos XVI-XVII, Proceedings of the III congreso del hombre y la cultura andina 21, Lima.

Glave, L. M.

1989 Trajinantes: caminos indigenas en la sociedad colonial siglos XVI/XVII, Instituto de Apoyo Agrario, Lima.

Göbel, B.

2002 La arquitectura de corrales del pastoreo: uso del espacio y sistemas de asentamientos en la Puna de Atacama (Susques), Estudios Atacameños 23.

Goepfert, N., E. Dufour, B. Gutiérrez y C. Chauchat

2013 Origen geográfico de camélidos en el período Mochica (100-800 AD) y análisis isotópico secuencial del esmalte dentario: enfoque metodológico y aportes preliminares, Bulletin de l'Institut Francais D'études Andines 42 (1), 25-48. https://doi.org/10.4000/bifea.869

\section{Goepfert, N. y G. Prieto}

2016 Offering llamas to the sea, en: N. Tripcevich y J. M. Capriles Flores (eds.), The archaeology of Andean pastoralism, 197-210, University of New Mexico Press, Albuquerque. 


\section{Gudemos, $M$.}

1998 Campanas arqueologicas de metal del noroeste argentino: entre el poder y los dioses, Anales del Museo de América 6, 111-146.

2013 Mapa cultural de los instrumentos musicales y objetos sonoros de metal arqueológicos: idiófonos (área andina centro-meridional), Revista Española de Antropología Americana 43, 579-597. https://doi. org/10.5209/rev_reaa.2013.v43.n2.44024

Harcourt, R.

1974 Textiles of ancient Peru and their techniques [traducción de por S. Brown], University of Washington Press, Londres.

Horn, P., S. Holz, S. Rummel, G. Aberg, S. Schiegl, D. Biermann, U. Struck y A. Rossmann

2009 Human and camelids ain river oasis of the Ica-Nasca-Palpa region in pre-hispanic times: insights from H-C-N-O-S-Sr isotope signatures, en: M. Reindel y G. Wagner (eds.), New technologies for archaeology: multidisciplinary investigations in Palpa and Nasca, Peru, 173-192, Natural Science in Archaeology, Springer, Berlin. https://doi.org/10.1007/978-3-540-87438-6_11

Isbell, B. J.

1978 To defend ourselves: ecology and ritual in an Andean village, Institute of Latin American Studies University of Texas at Austin y University of Texas Press, Austin.

Jouany, J.-P.

2000 La digestion chez les camélidés; comparaison avec les Ruminants, INRA Prod. Anim. 13 (3), 165-176.

Lecoq, P. y S. M. Fidel

2003 Prendas simbólicas de camélidos y ritos agropastorales en el sur de bolivia, Revista Textos Antropológicos $14,7-54$.

Lozada, M. C., J. E. Buikstra, G. Rakita y J. C. Wheeler

2009 Camelid herders: the forgotten specialists in the coastal senhorio of chiribaya, southern Peru, en: J. Marcus y R. Williams (eds.), Andean civilizations: a tribute to Michael Moseley, 351-377, Costen Institute of Archaeology Press, Los Angeles.

Mächtel, B., B. Eitel, G. Schukraft y K. Ross

2009 Built on sand: climate oscillation and water harvesting during the Late Intermediate Period, en: G. Wagner y M. Reindel (eds.), New technologies for srchaeology: multidisciplinary investigations in Palpa and Nasca, Peru, 39-46, Springer, Berkin. https://doi.org/10.1007/978-3-540-87438-6_3

Mallco, R.

2012 Proyecto de investigación arqueológica y puesta en valor del sitio arqueológico de Tacaraca -Ica, informe final presentado al Instituto Nacional de Cultural, Lima.

Menzel, D.

1959 The Inca occupation of the south Coast of Peru, Southwestern Journal of Anthropology 15 (2), 125-142. https://doi.org/10.1086/soutjanth.15.2.3628802

1976 Pottery style and society in ancient Peru : art as a mirror of history in the Ica Valley, 1350-1570,University of California Press, Berkeley

Murra, J. V.

1965 Herds and herders in the Inca state, en: A. Leeds y A. P. Vayda (eds.), Man, culture and animals, 185-216, vol. 78, American Association for the Advancement of Science, Washington, D.C.

1975 Formaciones ecónomicas y politicas del mundo andino, Instituto de Estudio Peruanos, Lima.

1980 The economic organization of the Inka state, Research in Economic Anthropology. Supplement, 1. JAI Press, Greenwich.

Neudecker, A.

1979 Archäologische forschungen im Nazca-Gebiet, Peru: das tal des Río Santa Cruz in präspanischer Zeit aus der Sicht der Forschungen prof. Dr. Ubbelohde-Doerings im Jahre 1932, Münchner Beitrage zur Amerikanistik, Bd. 3. Renner, Hohenschaftlarn.

Nielsen, A.

2000 Andean caravans, tesis de doctorado, Department of Anthropology, University of Arizona, University Microfilms, Ann Arbor. 
2001 Ethnoarchaeological perspectives on caravan trade in the South-Central Andes, en: L. A. Kuznar (ed.), Ethnoarchaeology of Andean South America: contributions to archaeological method and theory, 163-201, Ethnoarchaeological series, vol. 4, International Monographs in Prehistory, Ann Arbor.

Nigra, B., T. Jones, C. Stanish, J. Bongers, H. Tantaleán y K. Pérez

2014 The Chincha kingdom: the Archaeology and Ethnohistory of the Late Intermediate Period South Coast, Peru, Backdirt (December), 36-47.

Núñez A., L. y T. Dillehay

1979 Movilidad giratoria: armonía social y desarrollo en los Andes Meridionales, Universidad del Norte, Antofagasta.

Núnez A., L. y A. E. Nielsen (eds.)

2011 En ruta: arqueología, historia y etnografía del tráfico sur andino, Encuentro, Córdoba.

Orefici, G.

1985 Proyecto Arqueológico Italiano, informe de las temporadas 1984-85 presentado al Instituto Nacional de Cultura, Lima.

1987 Hacia la antigua Nasca: una contribucion italiana (edición de G. d. E. B. Continental), Embajada de Italia/Banco Continental, Lima.

1994 El recinto de los camélidos, en: Documentos de Trabajo 15-4, Memorias del VI Congreso de la Fiealc (1993), 49-53, Cesla/Universidad de Varsovia, Varsovia.

Pérez de Arce, J.

2001 Campanas metálicas santamarianas, Revista Musical Chilena 55, 59-74. https://doi.org/10.4067/S071627902001019600004

Proulx, D.

2007 Settlement patterns and society in the South Coast of Peru, a report to the H. John Heinz III Charitable Fund. http://wwwunix.oit.umass.edu/ - proulx/So_Coast_Peru.html [Accedido Enero 2015]

\section{Reindel, M.}

2005 Pinchango Alto: a gold miner's settlement in Palpa, southern Peru, en: P. Eeckhout y G. Le Fort (eds.), Wars and conflicts in prehispanic Mesoamerica and the Andes: selected proceedings of the conference organized by the Sociéte des Américanistes de Belgique with the collaboration of Wayleb (European Association of Mayanists), Brussels, 1385 (2002), 90-98, John and Erica Hedges Ltd., Oxford.

\section{Reindel, M. y J. Isla}

1998 Proyecto Arqueólogico Palpa: informe final de la temporada de campo 1997, Fundacion Suiza para Investigaciones Arqueológicas en el Exterior (FSLA), informe presentado al Instituto Nacional de Cultural, Lima.

Reindel, M. y J. Isla y K. Koschmieder

1999 Asentamientos prehispánicos y geoglifos en Palpa, costa sur del Perú, Beiträge zur Allgemeinen und Vergleichenden Archäologie 19, 314-381, Verlag Philipp von Zabern, Gegründet 1785, Mainz.

\section{Renneberg, R., S. Hummel y B. Herrmann}

2009 The Nasca and their dear creatures: molecular genetic analysis of pre-columbian camelid bones and textiles, en: M. Reindel y G. Wagner (eds.), New technologies for archaeology: multidisciplinary investigations in Palpa and Nasca, Peru, 193-206, Natural Science in Archaeology. Springer, Berlin.

Ross, J., D. Valenzuela, M. I. Hernández, L. Briones y C. M. Santoro

2008 More than motifs: the archaologicao analysis of rock art in arid regions of the southern hemispehere, Chungara 40 (Número especial), 273-294.

\section{Sandweiss, D.}

1992 Cronología del sitio «Lo Demas», Valle de Chincha e implicancias para la cronología tardía de Chincha, Boletin de Lima 79, 33-42.

Shimada, I.

2000 The Late prehispanic coastal states, en: L. Laurencich Minelli (ed.), The Inca world: the development of pre-Columbian Peru, A.D. 1000-1534, 49-110, University of Oklahoma Press, Norman. 


\section{Shimada, M. e I. Shimada}

1985 Prehistoric llama breeding and herding in the North Coast, American Antiquity 50, 3-25. https://doi. org/10.2307/280631

\section{Silverman, $\mathrm{H}$.}

1991 Informe final sobre el Proyecto de Prospección del Valle del Ingenio, informe presentado al Instituto Nacional de Cultura, Lima.

Siveroni, V.

2008 Informe de excavaciones, Proyecto de Excavaciones en Huayuri (Palpa, Ica), temporada 2005, informe presentado al Instituto Nacional de Cultura, Lima.

e.p. Household Integration and Population Aggregation in Late Prehispanic Nasca, tesis de doctorado, Institute of Archaeology, UCL, Londres.

Siveroni, V. y M. C. Ávila

2016 El rol de los camélidos en la ocupación tardía de Huayuri, cuenca norte del río Grande de Nasca: Evidencia artefactual, contextual y faunística, ponencia presentada en el XXIV Congreso Nacional de Estudiantes de Arqueologia «Giusepe Orefici», Ica, Peru, 5-10 de setiembre.

Siveroni, V. y A. Tiballi

2016 La producción doméstica de textiles en la ocupación prehispánica tardía de la región de Nasca: una mirada desde Huayuri, Palpa, Nuevo Mundo Mundos Nuevos. http://nuevomundo.revues.org/69901 [Accedido Diciembre 2016].

Siveroni, V., H. Tschauner, C. Rospigliosi, H. Falcon y A. Terukina

2004 Informe del Proyecto Arqueologico Huayuri (Pahuay), temporada 2002, informe presentado al Instituto Nacional de Cultura, Lima.

Spurling, G.

1992 The organization of craft production in the Inka State: the potters and weavers from Milliraya, tesis de doctorado, Department of Anthropology, Cornell Universuty, Itthaca.

Stobart, $\mathrm{H}$.

1996 Llama’s flutes: musical misunderstandings in the Andes, Early Music 24 (3), 470-482. https://doi. org/10.1093/em/24.3.470

Szpak, P.

2013 Stable isotope ecology and human-animal interactions in northern Peru, tesis de doctorado, Department of Anthropology, The University of Western Ontario, Electronic Thesis and Dissertation Repository. Paper 1634. http://ir.lib.uwo.ca/etd/?utm_source=ir.lib.uwo.ca\%2Fetd\%2F1634\&utm_medium=PDF\&utm_campaign=PDFCoverPages [Accedido Enero, 2015].

Szpak, P., , J.-F. Millaire, C. D. White y F. J. Longstaffe

2014 Small scale camelid husbandry on the North Coast of Peru (Virú Valley): insight from stable isotope analysis, Journal of Anthropological Archaeology 36, 110-129. https://doi.org/10.1016/j.jaa.2014.08.005

Szpak, P., D. Chicoine, J.-F. Millaire, C. D. White, R. Parry y F. J. Longstaffe

2016 Early Horizon camelid management practices in the Nepeña Valley, North-Central Coast of Peru, Environmental Archaeology 21 (3), 230-245. https://doi.org/10.1179/1749631415Y.0000000002

Tomka, S. A.

1994 Quinua and camelids on the Bolivian Altiplano: an ethnoarchaeolgoical approach to agro-pastoral subsistence production with an emphasis on agro-pastoral transhumance, tesis de doctorado, Anthropology, University of Texas at Austin, Austin.

Traslaviña, A.

2016 Nuevas perspectivas sobre el diseño del espacio colonial rural: el caso de Nieve Nieve y Avillay en el valle de Lurín, Primeros asentamientos urbanos en Iberoamerica (ss. XVI y XVII), Actas del III Seminario Internacional RII_UC Piura (edición de C. V. Pacheco), 265-284, Universidad de Piura, Lima.

Tripcevich, $\mathrm{N}$.

2010 Exotic goods, Chivay obsidian, and sociopolitical change in the South-Central Andes, en: C. Dillian y C. White (eds.), Trade and exchange: archaeological studies from history and prehistory, 59-73, Springer, New York. 


\section{Vaca de Castro, Cristóbal}

1908 Ordenanza de tambos, Revista Histórica 3, 427-492.

[1543]

Valdez, L.

1988 Los camélidos en la subsistencia Nasca: el caso de Kawachi, Boletín de Lima 57, 31-35.

\section{Vaughn, K.}

2000 Archaeological investigations at Marcaya: a village approach to Nasca sociopolitical and economic organization, tesis de doctorado, Department of Anthropology, University of California, Santa Barbara, University Microfilms, Ann Harbor.

\section{Wapnish, P. y B. Hesse}

1988 Urbanization and the organization of animal production at Tell Jemmeh in the Middle Bronze Age Levant, Journal of Near Eastern Studies 47 (2), 81-94. https://doi.org/10.1086/373259

\section{Watson, L.}

2009 Elites y camélidos: excavaciones en los sectores I y II en Pueblo Viejo Pucara, un asentamiento del Período Tardío en el valle de Lurín, tesis de licenciatura, Facultad de Letras y Ciencias Humanas, Pontificia Universidad Católica del Perú, Lima.

\section{Wheeler, J. C.}

2006 The Chiribaya: ancient Peruvian alpaca and llama herders, Camelid Quaterly September, 1-4.

Recepción: marzo de 2017 Aceptación: mayo de 2017 